\title{
A Framework for Conceptualizing Evidence Needs of Health Systems
}

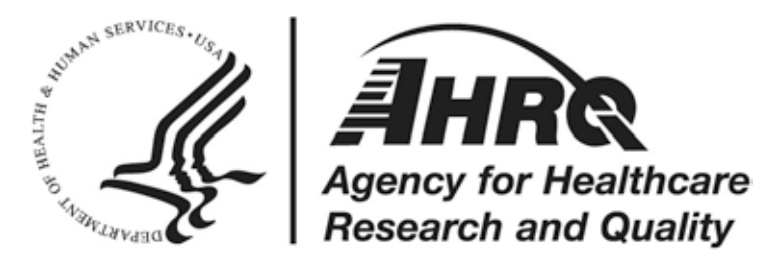




\section{A Framework for Conceptualizing Evidence Needs of Health Systems}

\section{Prepared for:}

Agency for Healthcare Research and Quality

U.S. Department of Health and Human Services

5600 Fishers Lane

Rockville, MD 20857

www.ahrq.gov

Contract No. 290-2012-0004-C

Prepared by:

Scientific Resource Center

Portland, OR

\section{Investigators:}

Karen Schoelles, M.D., S.M.*

Craig A. Umscheid, M.D., M.S.C.E.

Jennifer S. Lin, M.D., M.C.R.

Thomas W. Concannon, Ph.D., M.A.

Andrea C. Skelly, Ph.D., M.P.H.

Meera Viswanathan, Ph.D.

Christine Chang, M.D., M.P.H.

Elizabeth Kato, M.D., M.R.P.

Eric Bass, M.D., M.P.H.

Julia Lavenberg, Ph.D., R.N.

Kim Peterson, M.S.

Amanda Newton, Ph.D., R.N.

Evan Meyers, M.D., M.P.H.

Stacey Springs, Ph.D.

Vivian Christensen, Ph.D.

Nicole Floyd, M.P.H.

Celia Fiordalisi, M.S.

Jeanne-Marie Guise, M.D., M.P.H.

M. Hassan Murad, M.D., M.P.H.*

*Workgroup Leader

AHRQ Publication No. 18-EHC004-EF

December 2017 
This report is based on research conducted by the Agency for Healthcare Research and Quality (AHRQ) Evidence-based Practice Centers' Methods Workgroup. The findings and conclusions in this document are those of the authors, who are responsible for its contents; the findings and conclusions do not necessarily represent the views of AHRQ. Therefore, no statement in this report should be construed as an official position of AHRQ or of the U.S. Department of Health and Human Services.

\section{None of the investigators have any affiliations or financial involvement that conflicts with the material presented in this report.}

This research was funded through contracts from the Agency for Healthcare Research and Quality to the following Evidence-based Practice Centers: ECRI Institute-Penn Medicine (2902015-00005-I); Kaiser Permanente Center for Health Research (290-2015-00007-I); RAND (290- 2015-00010-I); RTI (290-2015-00011-I ); Pacific Northwest (290-2015-00009-I); The Johns Hopkins University (290-2015-00006-I); University of Alberta (290-2015-00001-I); Duke University (290-2015-00004-I); Brown University (290-2015-00002-I) and Mayo Clinic (2902015-00013-I).

The information in this report is intended to help EPCs and AHRQ understand health-systems need and use of evidence to inform their decisionmaking. This report is not intended to be a substitute for the application of clinical judgment. Anyone who makes decisions concerning the provision of clinical care should consider this report in the same way as any medical reference and in conjunction with all other pertinent information, i.e., in the context of available resources and circumstances presented by individual patients.

This report is made available to the public under the terms of a licensing agreement between the authors and the Agency for Healthcare Research and Quality. This report may be used and reprinted without permission except those copyrighted materials that are clearly noted in the report. Further reproduction of those copyrighted materials is prohibited without the express permission of copyright holders.

AHRQ or U.S. Department of Health and Human Services endorsement of any derivative products that may be developed from this report, such as clinical practice guidelines, other quality enhancement tools, or reimbursement or coverage policies, may not be stated or implied.

Persons using assistive technology may not be able to fully access information in this report. For assistance contact epc@ahrq.hhs.gov.

Suggested citation: Schoelles K, Umscheid CA, Lin JS, Concannon TW, Skelly AC, Viswanathan M, Chang C, Kato E, Bass E, Lavenberg J, Peterson K, Newton A, Meyers E, Springs S, Christensen V, Floyd N, Fiordalisi C, Guise JM, Murad MH. A Framework for Conceptualizing Evidence Needs of Health Systems. Research White Paper. (Prepared by Scientific Resource Center, under Contract No. 290-2012-0004-C). AHRQ Publication No. 18EHC004-EF. Rockville, MD: Agency for Healthcare Research and Quality; December 2017. Posted final reports are located on the Effective Health Care Program search page. https://doi.org/10.23970/AHRQEPCWHITEPAPER3. 


\section{Preface}

The Agency for Healthcare Research and Quality (AHRQ), through its Evidence-based Practice Centers (EPCs), sponsors the development of evidence reports and technology assessments to assist public- and private-sector organizations in their efforts to improve the quality of health care in the United States.

The reports and assessments provide organizations with comprehensive, science-based information on common, costly medical conditions and new health care technologies and strategies. The EPCs systematically review the relevant scientific literature on topics assigned to them by AHRQ and conduct additional analyses when appropriate prior to developing their reports and assessments.

To improve the scientific rigor of these evidence reports, AHRQ supports empiric research by the EPCs to help understand or improve complex methodologic issues in systematic reviews. These methods research projects are intended to contribute to the research base in and be used to improve the science of systematic reviews. They are not intended to be guidance to the EPC program, although may be considered by EPCs along with other scientific research when determining EPC program methods guidance.

AHRQ expects that the EPC evidence reports and technology assessments will inform individual health plans, providers, and purchasers as well as the health care system as a whole by providing important information to help improve health care quality. The reports undergo peer review prior to their release as a final report.

If you have comments on this Methods Research Project they may be sent by mail to the Task Order Officer named below at: Agency for Healthcare Research and Quality, 5600 Fishers Lane, Rockville, MD 20857, or by email to epc@ahrq.hhs.gov.

Gopal Khanna, M.B.A.

Director

Agency for Healthcare Research and Quality

Arlene S. Bierman M.D., M.S.

Director

Center for Evidence and Practice

Improvement

Agency for Healthcare Research and Quality
Stephanie Chang M.D., M.P.H.

Director

Evidence-based Practice Center Program

Center for Evidence and Practice

Improvement

Agency for Healthcare Research and Quality

Christine Chang M.D., M.P.H.

Task Order Officer

Center for Evidence and Practice

Improvement

Agency for Healthcare Research and Quality 


\section{Acknowledgments}

The authors gratefully acknowledge the input of the late Robert Lewis Kane, M.D., who was a member of our workgroup until his unexpected death on March 6, 2017. Dr. Kane stimulated the conversation of our workgroup with his ideas and challenges, and inspired creation of the initial framework for our efforts (See Appendix B).

The authors also acknowledge two health system representatives, Lucy Savitz, Ph.D., and Charles P. Friedman, Ph.D. for their feedback on our initial framework and draft report.

Dr. Savitz is currently the vice president of Health Research at Kaiser Permanente Northwest and the Director of the Center for Health Research for Kaiser Permanente Northwest and Hawaii.

She previously served as assistant vice president for delivery system science in the Intermountain Healthcare Institute for Healthcare Delivery Research. She was also an elected member of the Board of Directors for the High Value Health Care Collaborative, which includes 14 large health care delivery systems across the United States.

Dr. Friedman is the Josiah Macy Jr. Professor of Medical Education and Chair of the Department of Learning Health Sciences at the University of Michigan Medical School. He has extensive expertise in medical informatics and leads research on knowledge dissemination within the learning health systems, including at the national level. Previously, Dr. Friedman was the Deputy National Coordinator and Chief Scientific Officer at the Office of the National Coordinator for Health IT (ONC).

The authors additionally would like to gratefully acknowledge the contributions of Marguerite Koster, M.A., M.F.T. from the Southern California Kaiser Permanente Medical Group for providing the original data representing the Kaiser Permanente Southern California Evidence-Based Medicine (EBM) Services Unit. 


\section{A Framework for Conceptualizing Evidence Needs of Health Systems}

\section{Structured Abstract}

Objectives. To develop a framework for understanding the evidence needs of health systems to inform the AHRQ EPC Program future efforts.

Data sources. Three data sources were used: (a) peer-reviewed literature from a systematic search of English-language publications in MEDLINE from January 2007-April 2017, (b) original data from four programs serving health system requests for evidence syntheses, and

(c) input during a face-to-face meeting at AHRQ in June 2017 from health system stakeholders and EPC investigators.

Methods. Data were synthesized narratively and thematically. We developed an initial framework to guide discussion and qualitative analysis. We built consensus around themes and refinement of the framework through weekly phone conferences, electronic communications, and a face-to-face meeting of workgroup members and health systems experts.

Results. From the literature review, we found that health systems seek evidence to inform decisions about acquiring new or emerging medical technologies; implementation or expansion of service offerings; and selection of governance, finance or delivery system models. Studies emphasize a preference for rapidly completed, succinct and easily understood evidence syntheses with layered information presentations. Studies of tools for promoting health system use of evidence describe methods for clarifying how the evidence applies to the local and operational context and how evidence intersects with other considerations in decisionmaking. Data from the four evidence synthesis programs illustrate a breadth of questions addressed and report types used by health systems. Discussions with health system experts highlighted the importance of trustworthiness of the process for synthesizing published literature; trustworthiness of the evidence itself; mechanisms for integrating internally generated data with evidence from published literature; and evaluation, feedback and updating mechanisms facilitated by transforming the published literature into machine executable knowledge for use by decisionmakers.

Conclusions. We identified several domains to facilitate interaction between health systems and evidence synthesis producers. Successful engagement will require specifying the type of decision or question of the health system; type of evidence synthesis to best address the question(s) of interest; tools to promote the use of evidence; and a feedback or auditing mechanism to determine the impact of evidence integration into health system decisions. Both the trustworthiness of the evidence synthesis process and communication of the trustworthiness of the evidence are additional key domains. Partnerships with health systems are critical for understanding their evidence needs and establishing trust. 


\section{Contents}

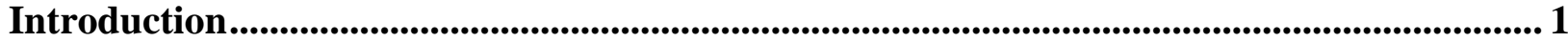

Methods.........................................................................................2

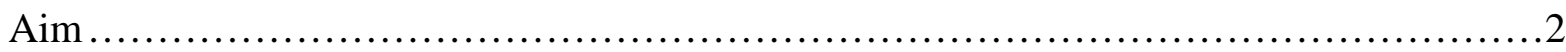

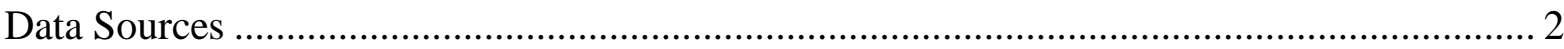

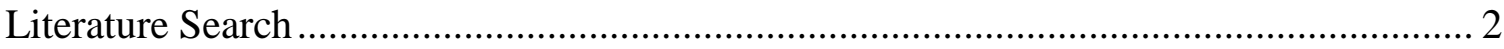

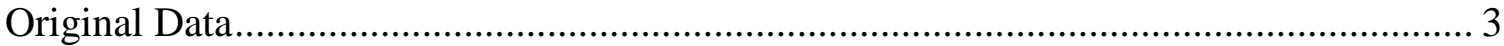

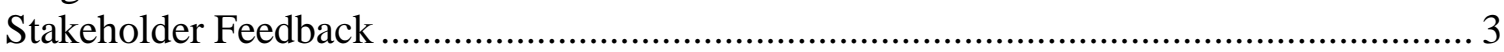

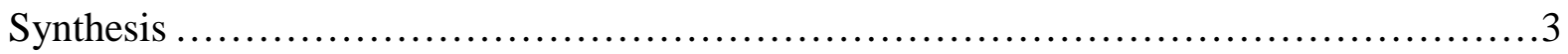

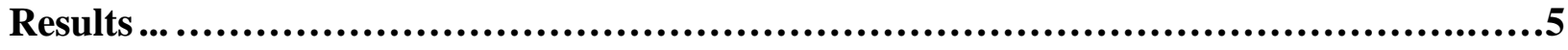

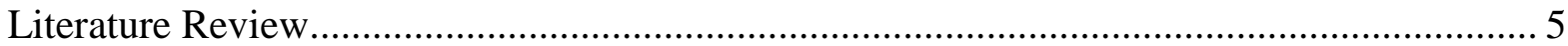

Types of Questions/Decisions for Which Health Systems Seek Evidence....................... 5

Types of Evidence Synthesis Sought by Health Systems ............................................ 7

Tools for Promoting Use of Evidence in Health System Decisions ................................ 9

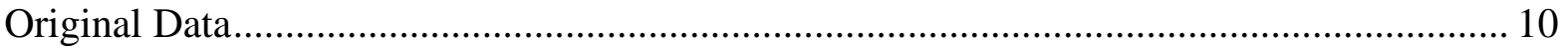

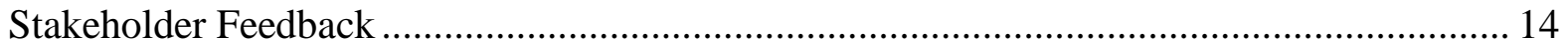

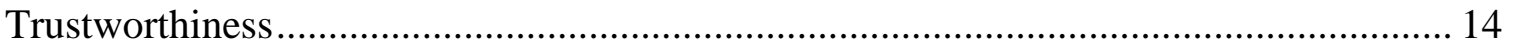

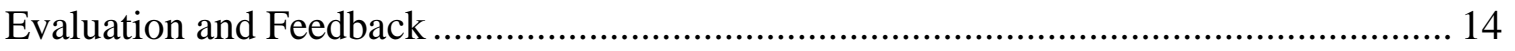

Preparing Evidence for Use by Learning Health Systems ......................................... 14

Engaging Health System Networks ..................................................................... 14

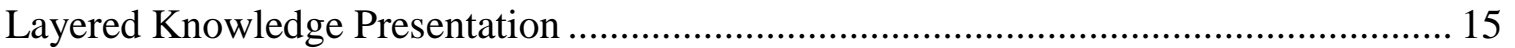

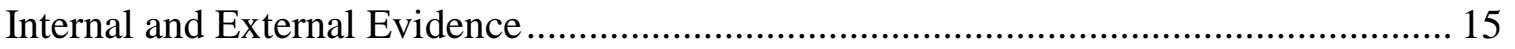

Evidence Synthesis Producer Engagement With Health Systems .................................. 15

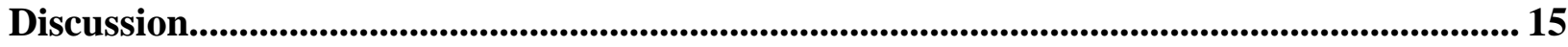

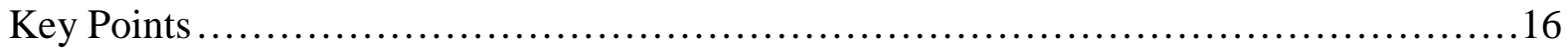

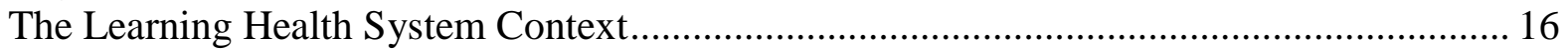

Recommendations for the AHRQ EPC Program ................................................................... 19

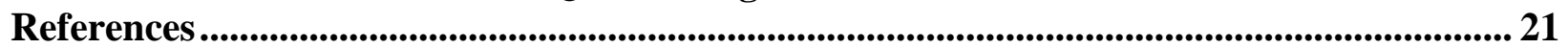

\section{Tables}

Table 1. Experience from four organizations: characteristics of evidence needs of hospitals

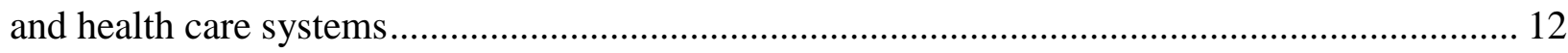

\section{Figures}

Figure 1. Research question and methodology ............................................................. 4

Figure 2. Domains or parameters to be specified for engagement of evidence synthesis programs with health systems

\section{Appendixes}

Appendix A. Search Strategy

Appendix B. Initial Framework

Appendix C. Evidence Tables 


\section{Introduction}

The field of systematic reviews has principally developed in response to the needs of clinicians, guideline groups, professional societies, and policy-makers, who required evidence summaries to answer clinical questions and underpin guidelines or policies. However, health care in the U.S. is increasingly delivered by large health systems involving one or more hospitals and clinical practice sites. This trend offers an opportunity to develop evidence synthesis products (e.g., systematic reviews, rapid reviews) to support these systems in their efforts to provide high quality evidence-based care, improve quality, and conduct practice-based research. Furthermore, the movement toward value-based purchasing and increased requirements for quality reporting is likely to increase the utility of evidence synthesis on a broad range of topics that extend beyond questions of clinical efficacy to questions about alternative strategies for improving health care delivery, product and practice standardization, patient safety and quality of care.

The Agency for Healthcare Research and Quality (AHRQ) has made working with health systems a priority, with a focus on helping systems transition to learning health systems. A learning health system was defined by the Institute of Medicine (IOM, now the National Academy of Medicine) Roundtable on Evidence-based Medicine as a system “designed to generate and apply the best evidence for the collaborative health care choices of each patient and provider; to drive the process of discovery as a natural outgrowth of patient care; and to ensure innovation, quality and value in health care."1

Well-established evidence synthesis programs such as the AHRQ Evidence-based Practice Center (EPC) Program have produced evidence reviews for more than two decades. These reviews have come to be recognized as a standard for rigor and quality across many disciplines, covering a wide range of topics that can be relied upon when making important decisions. This expertise may be particularly important when addressing high value care and health care delivery, which are likely to be complex in nature. Moreover, the EPC Program has developed considerable expertise in performing systematic reviews of complex multicomponent interventions. ${ }^{2-9}$ However, the program has not previously examined the scope of topics for which health systems seek evidence or how health systems access and use evidence-for what types of decisions and at what point in the decisionmaking process.

Of 250 reports produced by the EPC Program since 2011, 40 (16\%) address care delivery and population health topics that may be of interest to health systems (e.g., patient-centered medical homes, medication adherence, quality improvement strategies), and 159 (64\%) address clinical conditions that many health systems encounter. The remainder of topics covered methodologic issues of greatest interest to systematic reviewers. Previous work with health system representatives has revealed a need for evidence synthesis products that address specific decisions that health system leaders make and can be prepared quickly (e.g. evidence inventories, rapid reviews, automated approaches). ${ }^{10}$ Similarly, a study of health technology assessments (HTAs) produced by nine agencies during 2003-2006 ${ }^{11}$ suggested that decisions about governance, financial, and delivery arrangements require research evidence that informs problem definition, option framing and assessment, and implementation plans. These studies support the notion that health systems have unique evidence needs and that formats developed for clinical guideline developers may not meet the needs of health systems.

Evidence synthesis producers need to strengthen their partnerships with health systems to better understand their evidence synthesis needs. Strengthening such partnerships requires a conceptual framework that clarifies and categorizes their evidence needs. Such a framework 
could help the program and EPC researchers focus on the most appropriate evidence synthesis products for specific health systems.

The goal of this report is to present a conceptual framework to facilitate understanding of the potential areas for interaction between the EPC program and health systems. The framework categorizes the evidence needs of health systems, focusing largely on system use of external (i.e., published research) evidence. In addition, we explore the evidentiary needs and preferences for information presentation from health systems leaders participating in this project.

\section{Methods}

This project was commissioned by AHRQ as a methods project. The need for this project became apparent from years of EPCs' experience working with health systems, discussions with EPC Directors, EPC Methods Steering Committee meetings, and discussions with AHRQ leadership. This work is one of several complementary AHRQ projects about Learning Health Systems, including AHRQ's Comparative Health System Performance Initiative, which was designed to study how health care delivery systems promote evidence-based practices in care delivery.

\section{Aim}

The aim of this project was to develop a framework to identify and categorize the types of decisions for which health systems might seek external evidence, including evidence regarding health care delivery and organization, using the following questions:

a. What is the nature of the decision?

b. What is the level of evidence required by health systems?

i. What types of evidence would be needed for each type of decision?

ii. What type of review, format and time frame would be needed?

c. Who is involved in the decision?

d. Are there types of decisions where EPC reports could substantially improve the decisionmaking process and quality of care in health systems?

\section{Data Sources}

The data used in this study come from three sources: (a) literature search, (b) original data on evidence synthesis requests made to four evidence synthesis programs serving health systems, and (c) input from two health system stakeholders and EPC investigators, obtained during a faceto-face meeting at AHRQ in June 2017. A second workgroup's report addresses this topic through interviews with health system stakeholders.

\section{Literature Search}

Eligible publications summarize original data or present reviews, commentaries and opinion pieces that describe the research evidence needs of health systems. We defined a health system as at least one hospital and one group of physicians; or two or more health care provider organizations with common ownership, contractual integration (e.g., accountable care organizations) or formal referral arrangements. Eligible publications addressed who in a health system requested research evidence, what type of research evidence was requested, or why it was requested. We excluded non-English publications and those focusing on single health systems 
using their own local administrative or clinical data exclusively, rather than external research evidence, to inform decisions. We included studies from non-U.S. systems where the decisions were deemed to be similar to those faced by U.S. systems (e.g., U.K., Australia, Canada), but excluded those where the decisions are significantly different from those faced by U.S. systems.

We searched Ovid MEDLINE(R) Daily, Ovid MEDLINE(R) 1946-Present, and Ovid Medline Epub Ahead of Print, In-Process \& Other Non-Indexed Citations to identify relevant citations. Results were limited by publication date (2007-2017) and to English-language. The search identified 1553 candidate citations. Full search strategy details are available in Appendix A.

We identified additional references by reviewing bibliographies of relevant studies and contacting experts. References were uploaded into Abstrackr ${ }^{12}$ and dually reviewed for relevance using predetermined criteria. We extracted data on the characteristics of health systems, the individuals asking questions, payment or policy incentives informing questions and approaches, and types of research evidence used to address questions.

\section{Original Data}

A convenience sample of evidence synthesis review groups serving U.S. health systems was asked to provide a summary of the reviews performed for health systems over the last several years. These groups serve: Kaiser Permanente Southern California, a large integrated health system and not-for-profit health plan serving over 4.5 million members in Southern California; the Veteran's Health Administration (VHA), the largest integrated health care system in the United States; ECRI Institute, a not-for-profit health services research organization that conducts reviews for health systems, payers and provider groups under commission or subscription; and Penn Medicine, a large academic health system in Philadelphia, Pennsylvania. Information requested included the number and types of requests received for evidence syntheses, as well as the specialty and topic area of the requests.

\section{Stakeholder Feedback}

Two health system representatives (Lucy Savitz, Ph.D., from Intermountain Health Care and Kaiser Permanente Northwest, and Charles P. Friedman, Ph.D., Chair of the Department of Learning Health Sciences at the University of Michigan) were invited to review the approach and results of this work group and provide feedback. Additional stakeholder feedback was obtained from a second EPC workgroup that had conducted interviews with representatives of other health systems.

\section{Synthesis}

Data were synthesized narratively and thematically. We started by developing an initial framework to guide discussion and analysis (See Appendix B). We used weekly phone conferences, electronic communications and a face-to-face meeting of the workgroup to reach consensus on the initial framework and to modify it based on the three data sources. A summary of the research question and approach is depicted in Figure 1. 
Figure 1. Research question and methodology

\section{Aim}

To develop a framework for understanding evidence needs of health systems (What evidence is being requested, why and by whom? How can evidence synthesis be adapted to fit the needs of health systems?)

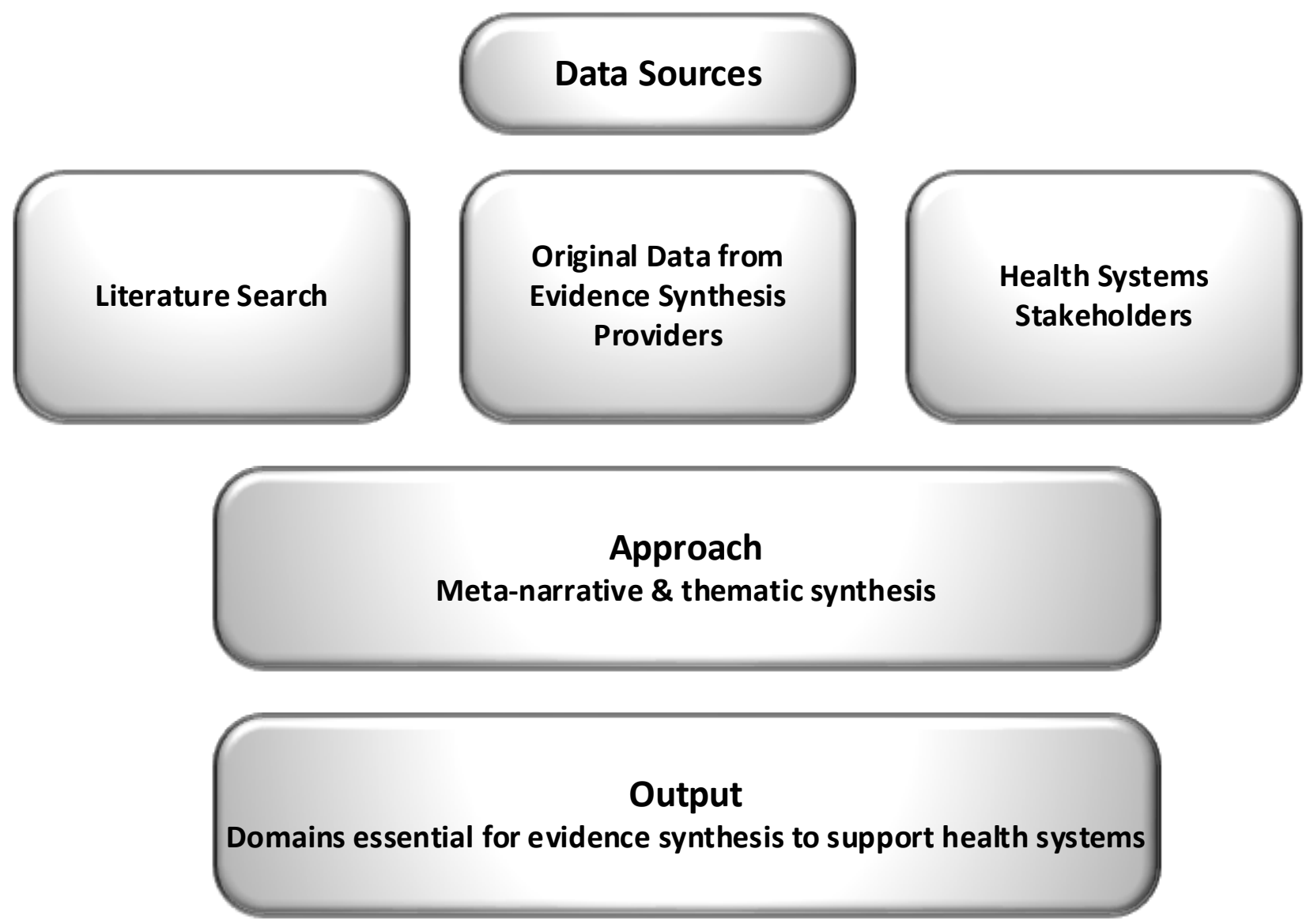




\section{Results}

\section{Literature Review}

From 1,591 candidate references, 166 were deemed relevant and reviewed in full text, and 46 articles were included. Eighteen of the studies contained original data, 11 were narrative reviews, 9 were commentaries or editorials, and 6 included their own frameworks for categorizing types of evidence needs or decisions made in the health system context.

\section{Types of Questions/Decisions for Which Health Systems Seek Evidence}

Three articles provided a broad categorization of evidence needs of health systems. Makkar $2015^{13}$ provides a framework with four ways in which research is used in decisionmaking: (1) to prioritize issues or actions; (2) to provide new ideas, understanding, or concepts to clarify thinking without directly influencing decisions; (3) to persuade stakeholders or to justify decisions; and (4) to meet external requirements, such as regulatory or funding mandates to use research evidence (e.g., Magnet status for hospitals). Ølhom $2015^{14}$ describes a systematic review of studies on the information needs of hospital managers for a European initiative (AdHopHTA) to strengthen the use of HTA by hospitals. They identified 74 types of information needs and categorized them into ten domains: health problem and current use of technology, description and technical characteristics of technology, clinical effectiveness, safety aspects, costs and economic evaluation, and ethical, organizational, social, legal, political and strategic aspects. Following the completion of the systematic review, the same researchers conducted face-to-face interviews with 53 hospital managers in 9 European countries to understand the managers' information needs regarding investments in new health care technologies. ${ }^{15}$ The most commonly cited needs were in the clinical effectiveness and economic domains, namely reimbursement and budget impact analysis, not societal level cost-effectiveness analysis. Interviewees also mentioned interest in the political and strategic domain, particularly regarding the hospitals' strategic research priorities, prestige-building, competition with other hospitals, and investments. 
Studies that reported on questions and decisions for which health systems seek evidence are summarized in Evidence Table C-1 in the Appendix. The studies show that health systems' questions can be asked at various levels, including the level of a committee, a unit/practice, department, hospital, or a whole health system level. Thematic review of the available studies demonstrates that the various categorization approaches converge into three overlapping areas. In Box 1, we summarize the three categories of decisions and questions for which health systems seek evidence.

\section{Box 1. Decisions and questions for which health systems seek evidence}

- Technology (e.g., drugs, devices, products and supplies) adoption, purchasing and disinvestment

- Health services offerings (e.g., service lines, community programs; care processes; quality improvement and safety interventions; implementation strategies; research programs)

- Governance, financial, and delivery arrangements (payment incentive programs; accountable care; public reporting; care coordination; budgeting and infrastructure planning; implications of population health needs; workforce planning regarding roles, training, and credentialing)

\section{Adoption of Medical Technology}

Much of the literature on decisionmaking and use of evidence in health systems focuses on the acquisition of health care technology (i.e., drugs, biologics, devices, equipment supplies, procedures, programs, support systems). ${ }^{16}$ Luce and Brown describe the results of a survey of 30 organizations including hospitals, health maintenance organizations (HMOs), public and private payers, and group purchasing organizations (GPOs). Participants from hospitals cited decisions on purchasing, controlling costs, marketing, and avoiding early obsolescence as reasons for their use of HTAs. ${ }^{17}$ Health maintenance organizations noted their obligation to cover interventions once they become "standard medical care" rather than "experimental” as impetus for decisions about examining new health care interventions.

Studies from the United States, United Kingdom and Australia showed that formulary decisions were one of the most common decisions for which health systems commonly required evidence. ${ }^{18,19}$ In one study, the most common technologies reviewed by HTA programs were drugs (24\%), devices (19\%), and care processes (12\%). ${ }^{18}$ Service managers in Australia considered safety and effectiveness the most important criteria when introducing or discontinuing new technologies. However, they acknowledged that budgetary considerations heavily influenced decisions about the uptake and diffusion of new technologies. ${ }^{20}$ Budget allocation and investment decisions were common reasons for seeking evidence in studies of hospital-based HTA included in a review by Gagnon. ${ }^{21}$

Several other studies described decisions for which organizations requested evidence syntheses, including choices between alternatives when standardizing products across a system, and choosing between vendors or manufacturers of similar products. ${ }^{18-24}$ A health system in Australia sought evidence to inform decisions about disinvesting in technologies and practices. ${ }^{25}$

\section{Health Services Offerings}

Several studies described use of evidence in strategic decisionmaking and implementation. Examples included addressing inequalities and disparities through developing new community programs and service lines. ${ }^{26}$ A clinical service line is an organizational strategy for planning, 
marketing and delivering multidisciplinary health care services defined by a clinical intervention, health condition, or population group. ${ }^{27}$

Others described initiatives for improving quality and safety of care by putting new processes in place, using tools such as clinical pathways. Several other studies reported evidence requested for determining implementation strategies for clinical programs or policies. ${ }^{18,19,22,28,29}$

When researchers in British Columbia, Canada, gathered researchers and decisionmakers from various levels in the six provincial health authorities to consider priority setting for future research in health care, ${ }^{30}$ they learned that staff were concerned about deciding how to effectively make decisions and set priorities, suggesting a need for evidence about the process of decisionmaking in health systems.

\section{Governance, Finance and Delivery Models}

Lavis $2010^{11}$ reviewed an inventory of HTAs produced by nine agencies during 2003-2006 and interviewed Canadian health care managers and policy makers. Decisions about governance, financial, and delivery arrangements require research evidence to inform problem definition, option framing and assessment, and implementation plans.

Several studies describe evidence needs in these categories. Cumpston and colleagues 2012 examined the work of the Cochrane Effective Practice and Organisation of Care (EPOC) group, which focuses on systematic reviews of professional, financial, organizational and regulatory interventions for improving practice and organization of health care services. ${ }^{31}$ After reviewing published EPOC review topics, the authors surveyed Australian health policymakers to identify gaps in the topics covered, and summarize their findings using the EPOC categories. Examples of the structural category include the need for evidence on interventions to improve population health and evidence to help the health system predict future demands for health services. Health systems the need to predict future demand to prepare for workforce recruitment, organization, and training, as well as to plan for infrastructure needs. ${ }^{31}$ Provider-oriented evidence needs include topics such as defining roles for allied health professionals and hospitalists, recruiting minorities to the workforce, and improving cultural competence. Patient-oriented needs include interventions to improve access and to serve special populations (e.g., rural, indigenous, refugees, prisoners) and interventions to promote community engagement in health service planning. Regulatory topics include the impact of credentialing of health professionals on safety and quality of care, and identifying interventions to improve coordination of services when there are multiple payers/funders involved. ${ }^{31}$ In addition, the authors of this and other studies identified the need for evidence to support financial decisions, including topics such as the impact of different funding models and financial incentives on demand for, quality of, and access to care. ${ }^{31,32}$ Makkar 2015 identified the need for evidence to support the response to organizational or legislative mandates. ${ }^{13}$

A survey of the operational partners of the U.S. Veterans Health Administration's Evidencebased Synthesis Program (VA ESP) showed that rapid reviews (median completion time 14.5 weeks) were commonly (72\%) requested in response to regulatory and policy directives. ${ }^{28}$ For example, a report that evaluated the quality of care provided by advanced practice nurses was requested to inform consideration of practice authority expansion. ${ }^{28}$

\section{Types of Evidence Synthesis Sought by Health Systems}

Several studies have examined types of products or formats of evidence syntheses intended for use by decisionmakers. In one previous EPC methodology project, rapid review products were categorized based on extent of synthesis. "Inventories" listed what evidence is available. 
"Rapid responses" presented best available evidence such as systematic reviews and health technology assessments with no formal synthesis. "Rapid reviews" synthesized the quality of and findings from the evidence, often including primary studies. "Automated approaches" generated meta-analyses in response to user-defined queries. ${ }^{33}$ In a second EPC methodology project, several end-users were interviewed (key informants including guideline developers, health care providers/health system organizations, research funders, and payers/health insurers). ${ }^{10}$ Informants described the use of evidence inventories "to stimulate discussion, challenge the status quo or get a sense of the literature when there is a pressing concern.” They reported that "rapid responses and rapid reviews may be more relevant for issues (often narrow questions) that arise within the clinical setting specific to a health system (where it may be more feasible to narrow the scope), or when interest is focused more on implementation (e.g., tailoring the evidence to a given region/setting).” One interviewee describing the tension between rigor and efficiency stated, "operationally-oriented folks are willing to take a risk on the absolute correctness of the answer in order to do something and to do it reliably across the delivery system."

The VHA ESP surveyed health system leadership about their use of the program's rapid reviews. $^{28}$ There was a high level of agreement that the rapid reviews were influencing the delivery system. A similarly designed study in a large academic health care system suggested the same. $^{18}$

Members of Pharmacy and Therapeutics committees (pharmacists and physicians from various health systems and organizations) participating in focus groups ${ }^{34}$ were asked about their use of AHRQ EPC Program Comparative Effectiveness Reviews (CERs). Only 26\% reported using the reviews in their organizations. Participants described them as not being sufficiently timely, specific, or conclusive for their purposes. Pharmacy and Therapeutics committees usually review new products, whereas CER reviews are more useful for evaluating therapeutic classes of existing drugs. The wide focus and lack of specificity were a challenge to use when making specific decisions. They also commented on the need for more decisive information whereas most CER reports were perceived to be inconclusive.

Wye $2015^{35}$ studied the use of evidence by local policymaking bodies in the U.K. and pointed out that many academic research products are not relevant to their decisions, arguing that generalizable evidence lacks local context: "Local information often trumped national evidence, academic research or information from other localities.” Commissioners, "will always struggle to apply systematic reviews and randomized controlled trials, because paradoxically the very qualities that create such context-free, gold standard research render the studies less useful to commissioners." 35 Instead, "commissioners want "killer" stories that are rich in context." ${ }^{35}$ In contrast, VHA executive level policymakers and their staff preferred RCTs, but also valued other types of evidence, such as case studies and patient preference studies. ${ }^{36}$

Others also mentioned the need for local contextual information or applicability information, and descriptions of the uncertainty of the findings. ${ }^{11,35}$ Such contextual information is critical for decisionmaking and is consistent with the GRADE Evidence to Decision framework, which describes several discrete factors, other than effectiveness evidence, needed to make decisions (e.g., cost effectiveness and resource use, equity, acceptability, feasibility and values). ${ }^{37}$

In contrast, other health services researchers experienced in engaging policymakers and health care managers argue that systematic reviews can be useful to these groups, and compiled a list of "myths" about the suitability of systematic reviews for use by decisionmakers. ${ }^{38}$ They attempted to counter these myths by reviewing evidence included in the Canadian Health 
Systems Evidence Website (www.healthsystemsevidence.org), which covers topics including governance, financial arrangements, delivery arrangements, and implementing change in health systems. While acknowledging that more systematic reviews addressing policymakers' questions are needed, they argued that systematic reviews can "level the playing field" when there are multiple stakeholders with different points of view. When all interested parties work from the same evidence, engagement is more likely. They also argued that "empty" systematic reviews (i.e., systematic reviews with no eligible studies to answer the question at hand) could be useful for decisionmaking. Finally, they note that exploring heterogeneity in systematic reviews can facilitate understanding about why interventions work in some settings and not others.

Additional descriptions are provided in Evidence Table C-2 in the Appendix. Together these studies identified several key characteristics of evidence synthesis products favored by health systems, as shown in Box 2.

\section{Box 2. Characteristics of evidence synthesis products favored by health systems}

- $\quad$ Short production times

- Timely topics

- Narrow focus; addressing specific questions related to technology acquisition or service line offerings

- Practical and implementable

- $\quad$ Provide guidance for action, even if evidence is less strong than ideal (e.g., case studies when controlled trials are not available)

- $\quad$ Provide contextual information (e.g., about cost, patient preferences and values, feasibility, acceptability) that supplement effectiveness evidence

- $\quad$ Incorporate local evidence and context

\section{Tools for Promoting Use of Evidence in Health System Decisions}

Although this question was not included in the initial proposed framework, the literature review suggested that this issue is likely important for health systems and can optimize their use of evidence. Gagnon 2014 conducted a systematic review of instruments to assess organizational readiness for knowledge translation in health care, identifying 26 instruments. ${ }^{39}$ A number of studies described self-assessment tools for use by health systems decisionmakers to evaluate readiness and resources for utilizing evidence in decisions (e.g., Catallo $2014^{40}$, Lefebre 2010, ${ }^{41}$ Gifford 2014 ${ }^{42}$, Gagnon 2014 ${ }^{39}$ )

Perrier $2011^{43}$ et al conducted a systematic review on interventions encouraging the use of systematic reviews by health policymakers and managers. In the single randomized trial identified, Dobbins $2009^{44}$ found that showing tailored messages combined with access to a registry of systematic reviews had a significant effect on policies made in a health department in Canada.

Ellen $2014^{45,46} 2013^{47}$ used surveys and qualitative studies to determine the barriers and facilitators for using evidence in health system decisionmaking. Establishing an environment that is conducive to use of evidence includes appropriate infrastructure, facilitating "push" efforts by knowledge brokers to disseminate research evidence to potential users, "pull” efforts by health system decisionmakers, "linkage and exchange” efforts facilitating relationships between researchers and knowledge users, and evaluation of knowledge translation efforts. Innis $2015^{48}$ also reported on such barriers and facilitators in a scoping review that emphasized the importance of organizational culture, leadership, linkage of evidence use to the organization's strategic direction, presence of champions and appropriate infrastructure. 
The focus group study with Pharmacy and Therapeutics committee members mentioned previously found the participants were interested in attending or completing a CER training program to help them use CER reviews in preparing evidence summaries for decisionmaking. In particular, they wanted training in evaluation of "evidence hierarchies," and wanted online course delivery. $^{34}$

In several studies, decisionmakers were interviewed or observed to identify preferences for presentation format. In general, they preferred summaries that were brief, presented in a "graded” format (key messages, executive summary) or presented verbally. 11, 18, 22, 35

Two systematic reviews ${ }^{49,50}$ addressed decisionmakers preferences for various derivative products based on systematic reviews. One found that decisionmakers described summary of findings tables with event rates and absolute differences as preferable. ${ }^{49}$ The other found that mailed bulletins with synopses of systematic reviews that were distributed to clinicians were associated with some practice improvement. ${ }^{50}$ Wye 2015 studied the use of evidence by local policymaking bodies in the U.K. and noted that policymakers preferred verbal over written presentation. $^{35}$

As described previously, health system decisionmakers often expressed a desire for more “conclusive” and “decisive” evidence. Studies by Makkar 2015 ${ }^{13}$, Aicken $2012^{51}$, Goetghebeur $2008^{52}$, Munn $2014^{53}$, and Munn $2014^{53}$ described approaches that may address this perceived need by providing tools such as multicriteria decision analysis (MCDA), conjoint analysis, decision analytic modelling, or other quantitative approaches to clarifying value judgments and incorporating evidence. These approaches would require partnership between evidence synthesis producers and health systems capable of manipulating and processing the evidence to make local decisions.

Box 3. Characteristics of tools for promoting use of evidence syntheses by health systems

- $\quad$ Preparation for using evidence: system self-assessment tools for use of evidence and knowledge translation

- $\quad$ Customized information delivery and access to information resources

- Health system infrastructure and local champions for use of evidence in decisionmaking

- $\quad$ Layered format that allows different users with different needs to access formats that range from a highly focused presentation to highly detailed information

- $\quad$ Preference for event rates, natural frequencies, and absolute differences, over relative measures

- Oral presentation of report findings to users

- $\quad$ Training and education for users

The studies relevant to this domain are found in Evidence Table C-3 in the Appendix.

\section{Original Data}

Original data were available from four evidence synthesis programs that addressed the research evidence needs of individual health systems: Kaiser Permanente Southern California (KPSC), Veterans Health Administration (VHA) Evidence Synthesis Program (ESP), ECRI Institute's Health Technology Assessment Information Service (HTAIS), and Penn Medicine Center for Evidence-based Practice (CEP). The experiences of these four centers are summarized in Table1.

The number of products created annually by each center varied widely, from over 300 products a year for organizations like ECRI and KPSC that performed rapid reviews and served a large number of hospitals, to approximately 30 a year for Penn CEP, which performs rapid 
reviews but serves fewer hospitals, to less than 20 a year for the VHA ESP, which commonly performs traditional reviews for the national VA program. Many requests received by ECRI Institute did not lead to the generation of new evidence reports (205/702, 29\%), and the requestor was directed to existing systematic reviews, evidence reports or other resources. Rapid products were the most common product performed except at the VHA (93\% of the ECRI HTAIS reports within 10 to 15 business days, 60\% of KPSC reports within 1 to 5 days as required by regulation for addressing patient requests, 86\% of Penn Medicine CEP reports within 3 months). A wide range of clinical and administrative decisionmakers requested evidence reviews, and the topics were similarly broad-ranging from evidence to guide clinical care; purchasing of medications and devices; procedural and non-procedural interventions; and processes of care. Topics addressed by each organization were dictated by the needs of their requestors or strengths of the organization. For example, almost 70\% of the VHA ESP reports addressed care processes, policies or non-drug, non-device interventions, while approximately $90 \%$ of ECRI reports addressed devices, procedures, implants, tests or other technologies. Data suggest that those requesting reports and the types of topics examined have changed over time as well. For example, the proportion of reports performed by the Penn CEP that were relevant to nursing practice increased from 6\% (2/35) in the center's first two fiscal years (2007-2008) to 31\% $(18 / 59)$ in the center's two most recent fiscal years (2015-2016). Similarly, a prior publication (Jayakumar 2016) describing the Penn CEP noted that the proportion of reports addressing policy, managerial, or organizational support systems increased from 7\% (7/109) in the center's first 4 years to 24\% (33/140) in their second four years.

Experience from the four centers is summarized in Table 1. 
Table 1. Experience from four organizations: characteristics of evidence needs of hospitals and health care systems

\begin{tabular}{|c|c|c|c|c|c|c|}
\hline Institution Description & $\begin{array}{c}\text { Study } \\
\text { Period } \\
\text { N }\end{array}$ & Product Type & $\begin{array}{l}\text { Requestor } \\
\text { Type }\end{array}$ & Technology Class & Clinical Specialty & Other Comments \\
\hline $\begin{array}{l}\text { ECRI HTAIS } \\
\text { Nonprofit health services } \\
\text { research organization } \\
\text { providing Web-based } \\
\text { Health Technology } \\
\text { Assessment Information } \\
\text { Service (HTAIS) to } \\
\text { hospital and third-party } \\
\text { payer members on a } \\
\text { subscription basis }\end{array}$ & $\begin{array}{l}\text { CY2016 } \\
307\end{array}$ & $\begin{array}{l}\text { 80\% Rapid } \\
\text { Response (1) } \\
\text { 13\% Product } \\
\text { Comparison } \\
(1) \\
7 \% \text { Special } \\
\text { Reports (2) }\end{array}$ & $\begin{array}{l}70 \% \text { Purchasing, } \\
\text { value analysis, or } \\
\text { supply chain } \\
\text { professionals } \\
12 \% \text { Clinical } \\
\text { departments } \\
10 \% \text { Nursing } \\
3 \% \text { Health technology } \\
\text { assessment groups } \\
3 \% \text { Medical staff } \\
2 \% \text { Strategic planning }\end{array}$ & $\begin{array}{l}\text { 47\% Devices } \\
21 \% \text { Procedures } \\
16 \% \text { Implants } \\
\text { 3\% Drugs } \\
\text { 3\% Biotechnology } \\
\text { 3\% Service } \\
\text { 2\% Assistive technology } \\
2 \% \text { Laboratory test } \\
\text { 1\% Diet/Nutrition } \\
\text { 1\% Health IT } \\
\text { 1\% } \\
\text { Complementary/Alternat } \\
\text { ive }\end{array}$ & $\begin{array}{l}\text { 24\% Surgery (general, bariatric, } \\
\text { cardiothoracic, neurosurgery, } \\
\text { plastic and transplant) } \\
8 \% \text { General medicine } \\
7 \% \text { Cardiology } \\
6 \% \text { Nursing } \\
6 \% \text { Orthopedic } \\
4 \% \text { Oncology } \\
4 \% \text { Gastroenterology } \\
4 \% \text { Clinical lab, diagnostic } \\
\text { imaging } \\
3 \% \text { Critical care } \\
3 \% \text { Infectious disease } \\
3 \% \text { Dermatology }\end{array}$ & $\begin{array}{l}307 \text { of } 495 \text { HTAIS reports } \\
\text { written in } 2016 \text { were for } \\
\text { hospitals or health systems. } \\
\text { Health systems had a } \\
\text { median of } 4.5 \text { hospitals per } \\
\text { system, range } 1 \text { to } 34 \\
\text { hospitals; } 61 \% \text { of systems } \\
\text { are moderately or highly } \\
\text { centralized; } 27 \% \text { of } \\
\text { hospitals have }<100 \text { beds; } \\
20 \% \text { are rural; } 31 \% \text { have no } \\
\text { academic affiliation. } \\
\text { Rapid responses are } \\
\text { completed in } 10-15 \\
\text { business days with no } \\
\text { formal synthesis } \\
\text { Product comparisons are } \\
\text { overviews of rapid } \\
\text { responses for multiple } \\
\text { brands of a technology or } \\
\text { product } \\
\text { Special reports are } \\
\text { qualitative reviews of } \\
\text { multiple brands and multiple } \\
\text { technologies or products for } \\
\text { particular service lines. }\end{array}$ \\
\hline $\begin{array}{l}\text { VHA ESP } \\
\text { Established in } 2007 \text { and } \\
\text { funded by QUERI. Has } 4 \\
\text { centers, each with a } \\
\text { University affiliation and } \\
\text { close ties to AHRQ } \\
\text { Evidence-based Practice } \\
\text { Centers. Governance } \\
\text { provided by a } \\
\text { Coordinating Center and } \\
\text { a Steering Committee of } \\
\text { VHA leadership. }\end{array}$ & $\begin{array}{l}\text { FY2011- } \\
2016 \\
98\end{array}$ & $\begin{array}{l}\text { 17\% Rapid } \\
\text { Review (2) } \\
\text { 8\% Evidence } \\
\text { Map (3) } \\
60 \% \\
\text { Traditional } \\
\text { Review (3) }\end{array}$ & $\begin{array}{l}94 \% \text { non-academic } \\
\text { Subject-Matter } \\
\text { Experts with VA } \\
\text { operation decision- } \\
\text { making authority, } \\
\text { including National } \\
\text { Program Offices, } \\
\text { Central Office, and } \\
\text { Chief Consultants }\end{array}$ & $\begin{array}{l}\text { 31\% Care processes } \\
\text { 19\% Policy } \\
\text { 18\% Non-drug, non- } \\
\text { device intervention 14\% } \\
\text { Devices } \\
\text { 12\% Test, scales, risk } \\
\text { factors } \\
\text { 8\% Drugs } \\
\text { 3\% Medical/surgical } \\
\text { procedures } \\
\text { 3\% Support system } \\
\text { (e.g., counseling) } \\
\text { 3\% Prevalence, } \\
\text { epidemiology } \\
\end{array}$ & $\begin{array}{l}\text { 44\% General medicine } \\
10 \% \text { Cardiology } \\
8 \% \text { Pain medicine } \\
5 \% \text { Surgery (general, } \\
\text { cardiothoracic) } \\
4 \% \text { Ophthalmology } \\
3 \% \text { Gastroenterology } \\
3 \% \text { Nursing } \\
3 \% \text { Oncology } \\
2 \% \text { Nephrology } \\
2 \% \text { Neurology } \\
2 \% \text { Sleep medicine } \\
1 \% \text { Geriatrics } \\
1 \% \text { Infectious disease }\end{array}$ & $\begin{array}{l}35 \% \text { of all reports include } \\
\text { meta-analysis } \\
36 \% \text { of all reports have led } \\
\text { to journal publications } \\
100 \% \text { of reports are publicly } \\
\text { available within } 1 \text { year }\end{array}$ \\
\hline Penn CEP & $\begin{array}{l}\text { FY2006- } \\
2016\end{array}$ & $\begin{array}{l}\text { 58\% Rapid } \\
\text { Review (2) }\end{array}$ & $\begin{array}{l}\text { 33\% Clinical } \\
\text { departments } \\
17 \% \mathrm{CMO}\end{array}$ & $\begin{array}{l}21 \% \text { Drugs } \\
21 \% \text { Care processes } \\
17 \% \text { Devices }\end{array}$ & $\begin{array}{l}16 \% \text { Nursing } \\
11 \% \text { General medicine } \\
9 \% \text { General surgery }\end{array}$ & $\begin{array}{l}\text { 14\% performed original } \\
\text { meta-analyses }\end{array}$ \\
\hline
\end{tabular}




\begin{tabular}{|c|c|c|c|c|c|c|}
\hline Institution Description & $\begin{array}{c}\text { Study } \\
\text { Period } \\
\text { N }\end{array}$ & Product Type & $\begin{array}{l}\text { Requestor } \\
\text { Type }\end{array}$ & Technology Class & Clinical Specialty & Other Comments \\
\hline $\begin{array}{l}\text { Evidence-based practice } \\
\text { center established in } 2006 \\
\text { to serve a large urban } \\
\text { academic health care } \\
\text { system }\end{array}$ & 308 & $\begin{array}{l}28 \% \text { Advisory } \\
\text { (2) }\end{array}$ & $\begin{array}{l}\text { 11\% Purchasing } \\
\text { 10\% Nursing } \\
\text { 8\% Quality } \\
\text { 8\% Formulary } \\
\text { 7\% Administrative } \\
\text { departments }\end{array}$ & $\begin{array}{l}\text { 12\% Policy } \\
11 \% \text { Tests } \\
8 \% \text { Procedures } \\
5 \% \text { Biologics } \\
5 \% \text { Support systems }\end{array}$ & $\begin{array}{l}8 \% \text { Critical care } \\
7 \% \text { Orthopedics } \\
7 \% \text { Cardiology } \\
6 \% \text { Hematology } \\
4 \% \text { Infectious diseases } \\
4 \% \text { OBGYN } \\
3 \% \text { Oncology }\end{array}$ & $\begin{array}{l}31 \% \text { performed GRADE } \\
\text { assessments } \\
13 \% \text { informed informatics } \\
\text { tools }\end{array}$ \\
\hline
\end{tabular}

Abbreviations: CMO, Chief Medical Officer; CY, calendar year; ECRI HTAIS, ECRI Institute Health Technology Assessment Information Service; FY, fiscal year; GRADE; Grading of

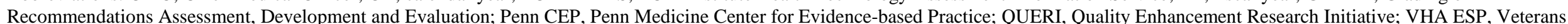

Health Administration Evidence-based Synthesis Program; KPSC EBM Services, Kaiser Permanente Southern California Evidence-Based Medicine (EBM) Services Unit

Note: (1) Takes less than 1 month; (2) takes less than 3 months; (3) takes 8 months or more. Rapid Responses and Rapid Reviews are defined in Hartling 2017. 


\section{Stakeholder Feedback}

Two health system representatives, Lucy Savitz, Ph.D., M.B.A. and Charles P. Friedman, Ph.D. provided feedback on our initial framework and draft report. Our stakeholders' perspectives on how the EPC program can best interact with learning health systems can be summarized in the following themes:

\section{Trustworthiness}

Drs. Savitz and Friedman introduced a new domain to the framework-trustworthiness of evidence. This trustworthiness was described in two ways:

- How trustworthy is the evidence? Health systems making decisions based on the evidence need to know the reviewers' level of confidence in the estimates of effect provided in the evidence summaries. This description is analogous to the strength of evidence (SOE) levels used by the EPC program when conducting systematic reviews.

- How trustworthy is the evidence synthesis group and how credible is the review process? Stakeholders emphasized the importance of trust and partnership between the health system and the evidence synthesis team and voiced that such trust is critical to acceptance of evidence summaries by health systems.

They also mentioned that a system might not trust the assigned SOE if it contradicts data or observations derived from their local setting. They expressed the concern that excessive labeling of evidence as low or insufficient is, in general, not helpful to health systems because they need to make decisions and act in real time, and cannot wait for future studies. They also mentioned the need for evidence summaries that present more decisive and practical results.

\section{Evaluation and Feedback}

These health systems' representatives described the need for evaluation, reassessment and feedback about the use of evidence in health systems. Such evaluation serves as a tool for continuous quality improvement, can close the loop on evidence uptake, and demonstrate barriers for using summarized evidence in decisionmaking. They described a conceptual model in which knowledge is available in a machine executable form, and a learning cycle in which data transitions to knowledge, then knowledge transitions to practice, and finally practice provides additional data and process feedback.

\section{Preparing Evidence for Use by Learning Health Systems}

Drs. Savitz and Friedman suggested a role for evidence synthesis producers to assist in packaging and continuously updating evidence for real-time use by clinicians and other decisionmakers in learning health systems, with the vision of incorporating evidence into health information technology systems of the future. Such a role aligns with the concept of learning health systems.

\section{Engaging Health System Networks}

Our health systems stakeholders mentioned a possible need for evidence synthesis programs to engage with networks of health systems (e.g., High Value Healthcare Collaborative) and data analytics services (e.g., Flatiron Health, ASCO CancerLinQ ${ }^{\mathrm{TM}}$ ), which may help identify and address research evidence needs across health systems as they evolve and change. 


\section{Layered Knowledge Presentation}

Drs. Savitz and Friedman corroborated the importance of layered information that starts with key messages (which are important for certain types of users within health systems) followed by information that is more detailed (for other users who want to focus on implementation or have other particular needs).

\section{Internal and External Evidence}

Our stakeholders clearly differentiated between external evidence (summarized from published literature) and internal evidence (derived from the system's own electronic health records or other local datasets), and expressed the importance of both types of evidence.

\section{Evidence Synthesis Producer Engagement With Health Systems}

Lastly, Drs. Savitz and Friedman requested that this workgroup provide, in addition to a framework, recommendations that facilitate engagement of evidence synthesis producers with health systems.

\section{Discussion}

In this report, we sought to develop a framework to facilitate understanding of the areas of potential interaction between evidence synthesis producers and health systems. After using several data sources including published literature, original data from evidence synthesis programs, and obtaining feedback from health systems stakeholders, we identified several domains that may help facilitate interaction between health systems and evidence synthesis producers and may aid in providing evidence summaries catered to the needs of health systems.

Successful engagement will require specifying the following:

- type of decision or question(s) of the health system,

- type of evidence synthesis or evidence synthesis product that will best address the question,

o evidence synthesis users within the health system

o optimal timing for evidence synthesis delivery during the decisionmaking process

- tools required to promote the use of evidence (which could be developed by the evidence synthesis program or by the health system), and finally a

- feedback or auditing mechanism to determine the success and impact of evidence integration into health system decisions.

Trustworthiness of the process of the evidence synthesis and communication of the trustworthiness of the evidence is an additional key domain.

These domains can serve as a taxonomy and facilitate engagement with the health system (Figure 2). 
Figure 2. Domains or parameters to be specified for engagement of evidence synthesis programs with health systems
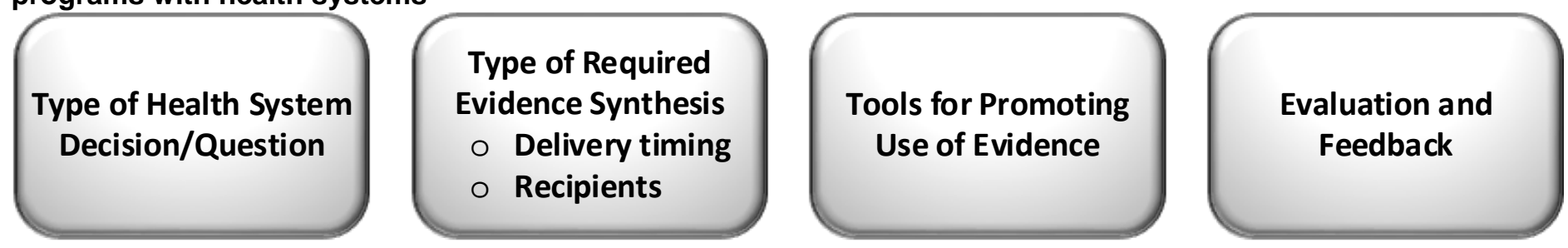

\section{Trustworthiness of Evidence and Evidence Synthesis}

\section{Key Points}

- Our review suggests that health system leaders' decisions for which evidence is needed commonly include the acquisition of medical technology, including interventional devices and pharmaceutical interventions; the implementation or expansion of service line offerings; disinvestment and deimplementation of technologies: improvements in care processes; and the selection of governance, finance and service delivery models.

- Health systems often are interested in evidence for newer and emerging interventions.

- Health systems often require evidence summaries that are completed rapidly (i.e., in 4-12 weeks or less) with succinct, easy-to-grasp conclusions with practical guidance for action even if the evidence is weak or inconclusive, and layered information presentation.

- Partnerships and reciprocal trust are essential for collaboration between evidence synthesis producers and health systems.

- For evidence to be believable and implementable by a health system, evidence synthesis producers should present it with the local and operational context in mind.

\section{The Learning Health System Context}

Much of the discussion about learning health systems focuses on the tremendous amounts of data each system can generate from patient encounters, including genomic data. ${ }^{54}$ In addition to using data within an individual system, learning health systems are forming data networks with a goal of generating new knowledge across organizations. However, there is clearly a role for synthesized external evidence in promoting the learning process. As described in one of the reports in the IOM series on learning health care systems, "A learning health care system depends on evidence to promote improvements in care delivery processes and patient care and overall system improvement. Consequently, health researchers are critical partners in generating knowledge on the effectiveness and value of interventions and care protocols."55

McGinnis, writing about the application of evidence-based medicine to learning health systems, describes a process in which systems with effective clinical data systems capture patient outcomes resulting from "best practice" and feedback the lessons to generate new knowledge that will facilitate customization for individual patients. ${ }^{1}$ This interaction between external and internal evidence is critical in learning health systems. This echoes what we heard from our 
health systems' experts, who clearly differentiated between external evidence (i.e., from the research literature) and internal evidence (derived from the system's own electronic health records or other local datasets) and expressed the need for both types of evidence. External evidence can provide the overarching comparative effectiveness inferences with strength of evidence (SOE) ratings, whereas internal evidence is useful to contextualize the external evidence and aid in its implementation. Internal evidence may also help fill the research gaps of external evidence. Mitchell 2010, writing about the Penn Medicine CEP has described their experience gathering external evidence and supplementing with collection of local evidence and contextual information from the health system. ${ }^{56}$

In a workshop held by the IOM on "engineering a learning healthcare system, ${ }^{55}$ Brent James described the process for integrating evidence into clinical care at Intermountain Healthcare. After identifying high priority clinical processes, defined by volume and risk to patients, the organization charges teams with developing evidence-based guidelines that can be embedded in the clinical workflow. Intermountain is able to measure variance from these "shared baselines" which is used to understand the degree of variation based on patient factors versus professional factors. He noted that typically 5 to 15 percent of the content of these protocols is routinely adapted to meet the needs of individual patients, an approach known in quality theory as "mass customization.” Evidence synthesis producers could collaborate with health systems to help to summarize evidence for such protocols. After implementing protocols, health systems could provide data back to evidence synthesis groups for analysis of variations and updating of the evidence with this internal evidence as well as more recently published external evidence.

Even sophisticated health systems may need assistance identifying best practice. For example, Raymond Baxter of Kaiser Permanente described an effort to gather input from clinical leaders in the Kaiser health system to find the questions for which they needed answers to meet the "triple aim": (1) Improving health care for individuals along six dimensions [safety, effectiveness, patient-centeredness, timeliness, efficiency, and equity]; (2) Improving the health for populations by attacking causes of ill health such as poor nutrition, physical inactivity, and substance abuse; and (3) Reducing, or at least controlling, the per capita cost of care. ${ }^{57} \mathrm{He}$ received 342 questions from across the organization. Baxter was surprised to learn that "between 25 and 30 percent of the questions already had answers, though the evidence was not known or available to those who proposed those questions." 58

One mechanism for delivering evidence-based guidance at the point of care is clinical decision support. Collaborations between evidence synthesis programs and clinical decision support developers are important for understanding the best ways to deliver syntheses for this purpose. Guideline syntheses, in which different approaches to care of patients with similar conditions are analyzed and harmonized alongside current evidence, may be useful products for this purpose. Another possible strategy is synthesis of evidence to inform quality or performance measures. In either case, feedback from health systems to evidence synthesizers about the outcomes of care would be critical for real improvements in patient care.

The belief that evidence synthesis producers only consider randomized controlled trials conducted in highly selected populations was noted in the literature and in discussions with the health system experts. The EPC Program, like other evidence synthesis programs, has called for inclusion of nonrandomized studies and other observational studies as a matter of course. ${ }^{59}$ Unfortunately, the perception persists that evidence syntheses are unlikely to address "real world" situations. The Program has recently invested in methods development for evaluating complex multicomponent interventions, ${ }^{3-9}$ much of which is applicable to the concerns of health 
systems. Other work has addressed ratings of SOE for complex interventions ${ }^{60}$ and for synthesizing evidence when meta-analyses are not possible; ${ }^{61}$ both scenarios are common for interventions considered by health systems. Other authors have provided similar arguments suggesting that a broad definition of evidence including observational studies is necessary for external evidence to be used in system level decision making; ${ }^{62}$ and attributing the lack of use of evidence by system level decisionmakers to the historical focus of evidence producers on individual clinicians’ needs (as opposed to operational, delivery and policy needs). ${ }^{63}$

In describing core features of the learning health system envisioned by the IOM Roundtable on Evidence-based Medicine, McGinnis discusses the need for a "trusted scientific intermediary" that can "broker the perspectives of different parties" in determining what constitutes best practice and how such evidence should be interpreted and applied. ${ }^{1}$ This echoes the point made by our stakeholders that health systems need assurance of the trustworthiness of both the evidence and the evidence synthesis producers.

Although the full series has not yet been published, Harris and colleagues at the Australian public health system, Monash Health, have begun to report their experience with such a process. This health system, which includes six hospitals and multiple outpatient and long-term care facilities, operates under a state determined fixed budget. In response to economic pressures, the Monash Health Centre for Clinical Effectiveness (CCE), an Evidence Based Practice (EBP) Hospital Support Unit, undertook the Sustainability in Health care by Allocating Resources Effectively (SHARE) program to approach disinvestment in practices that are unsafe, inefficient, ineffective, or less effective than alternatives. This series of publications describes the steps taken by the system to identify opportunities for change, develop proposals for supporting the change, implement the proposals, and evaluate the extent and impact of the change. The authors state "Each step is underpinned by the principles of evidence-based practice to ensure that the best available evidence from research and local data, the experience and expertise of health service staff and the values and perspectives of consumers are taken into account." Although authors do not use the term "learning health system" in the papers, it is clear that the goal of the project is to create a system that implements evidence, learns from the implementation, and feeds that learning back into the system and larger health care community. ${ }^{25,64,65}$

In summary, gaps exist between the needs of health systems and traditional evidence synthesis products in terms of topics covered, formats in which the synthesis is presented, and time for production. Evidence synthesis programs can support health systems by providing rapid, focused and layered summaries, addressing a broad range of topics of relevance to health systems, and by including contextual and operational evidence from local sources when available. Evidence synthesis producers need to strengthen their partnerships with health systems to better understand their evidence synthesis needs and to determine the most appropriate synthesis products for particular systems and decisions. We have proposed a framework to facilitate discussion to this end.

Based on our review and interaction with stakeholders from health systems, we next offer several recommendations for how the AHRQ EPC Program can better support health systems' uptake of evidence. 


\section{Recommendations for the AHRQ EPC Program}

The IOM challenged research funding agencies to promote research into barriers to use of evidence at the point of care and to support research methods for improving the usefulness and accessibility of local (patient outcome data) and external (published research) evidence for patients and clinicians. ${ }^{66}$

Our work group discussed possible roles for the AHRQ EPC Program in meeting the evidence needs of learning health systems in the United States. Methods work already performed by the Agency that is relevant to decisionmaking by health systems includes work on methods for synthesis of evidence on complex interventions, such as interventions used by health systems to support quality improvement and healthcare delivery. Other methods research performed by the AHRQ EPC program relevant to health systems are those projects related to the production of rapid evidence synthesis products, including projects on rapid reviews and horizon scanning.

The former AHRQ Director, Dr. Andrew Bindman, commented that most health care organizations need help to develop processes to adopt and generate evidence. He stated that AHRQ "is the federal agency best positioned to serve as a facilitator that can help health care organizations make this transition [to learning health care systems],” based on the Agency's experience developing methods for evaluating quality of evidence. He proposed that health systems could use these methods to judge the quality of both internal and external published evidence. He suggested that AHRQ could engage with health systems in "collaborative problem solving" as a means of learning how to support them. ${ }^{67}$

We considered roles that may be both desirable and feasible for AHRQ, given budgetary constraints and the complexity of current contracting mechanisms, and offer the following suggestions:

1. Create a standing advisory committee of health system leaders who can advise AHRQ on health system needs. Sponsor ongoing discussion forums with health systems for knowledge exchange (what evidence synthesis can provide; what health systems need) to

a. Establish relationship/rapport

b. Understand the timing and process of decision making

c. Better understand distinct needs of different types of health systems and what they have in common in order to better consider how AHRQ/EPC work may best fit

d. Enhance awareness of what AHRQ/EPCs have done, may be able to help with

e. Identify specific topics of interest for which there are non-urgent decisional needs (i.e., situations that match a feasible timeline for the EPC program to produce a review). This might include particularly challenging topics of interest to multiple health systems (e.g., High Value Healthcare Collaborative; Vizient ${ }^{\mathrm{TM}}$ University Health System Consortium)

f. Identify specific topics that fit technical brief, topic brief, or horizon scan paradigms and time lines

g. Identify topics related to implementation, disinvestment, operational, delivery and policy needs

2. Sponsor methods work related to integrating local health system evidence (i.e., clinical and operational data) with external published research evidence, including through pilot projects between health systems and EPCs.

3. Sponsor methods work to assess or develop tools to assist health systems in applying evidence to decisions: 
a. Explore ways to digitally enable data from evidence synthesis to facilitate the easy reuse, update, or extraction of findings into health information technology systems or other derivative products.

b. Develop brief audio versions or PowerPoint slides depicting key messages for topics of interest to health systems. Layer information using the "bite, snack, meal" concept. Provide training for EPCs on plain language concepts and examples. Explore ways to "push" information to more health systems through social media, e-mail, etc.

c. Strengthen the accessibility, usability and functionality of the EPC Program Web sites (https://www.ahrq.gov/research/findings/evidence-based-reports/search.html and https://effectivehealthcare.ahrq.gov/) so that reports can be easily identified, retrieved and used by health systems. Create a set of criteria which can be used to define those reports of most interest to health systems (e.g., compare alternative approaches to delivery, address healthcare quality or safety measures, clinical informatics), and create a flag or icon next to those reports.

d. For those reports meeting criteria of particular interest to health systems, a health system implementation toolkit could be published alongside the original report.

4. Involve interested health system partners and decisionmakers in the scoping for reviews they have nominated to identify their highest priority needs, with a goal of producing reviews that are focused, timely and relevant.

5. Leverage previous program experience with horizon scanning, topic briefs developed for program planning, and methods work on rapid reviews to develop new evidence synthesis products tailored to health systems. Engagement of health systems in the development process may promote trustworthiness in the EPC program, evidence synthesis process, and resulting product.

6. Shorten the time required to produce evidence reviews while maintaining a systematic rigorous approach. This could include

a. More flexible contractual mechanisms such as non-competitive assignments for evidence products or allowing for bundling of topics so contracting only has to be done once (e.g., one EPC will do 3 brief products in a 6-12 week time frame over the next 6 months)

b. Reduction of the various layers of public, peer and intra-agency review of reports

c. Reorganization of the production process.

7. Consider when certain types of contextual information, including information on intervention components, intervention implementation, and feasibility, should be included in EPC Program reviews to improve usefulness for health system decisionmaking.

8. Explore mechanisms for identifying emerging health system types not yet represented in the literature and understanding their evidence needs.

9. Facilitate discussion with groups making large-scale efforts to improve health system decisionmaking through incorporation of evidence. Understanding how these systems develop a learning cycle with measurement of impact can inform AHRQ's efforts in this area.

10. Partner with organizations closely aligned with health systems such as the Advisory Board, American Nurses' Credentialing Center Magnet Program, the American Hospital Association, ECRI Institute, Hayes Inc., and Vizient Inc. to disseminate report findings. 


\section{References}

1. McGinnis JM. Evidence-based Medicine Engineering the Learning Healthcare System. Stud Health Technol Inform. 2010;153:145-57. PMID: 20543243.

2. Guise J-M, Chang C, Viswanathan M, et al. Agency for Healthcare Research and Quality Evidence-based Practice Center methods for systematically reviewing complex multicomponent health care interventions. J Clin Epidemiol. 2014;67(11):1181-91. PMID: 25438663. https://doi.org/10.1016/j.jclinepi.2014.06.01 0 .

3. Guise J-M, Chang C, Butler ME, et al. AHRQ Series on complex intervention Systematic Reviews-Paper 1: An introduction to a series of papers that provide guidance and tools for reviews of complex interventions. J Clin Epidemiol. 2017; PMID: 28720511. https://doi.org/10.1016/j.jclinepi.2017.06.01 1 ..

4. Kelly MP, Noyes J, Kane RL, et al. AHRQ series on complex intervention systematic reviews-Paper 2: Defining Complexity, Formulating Scope and Questions. J Clin Epidemiol. 2017; PMID: 28720514. https://doi.org/10.1016/j.jclinepi.2017.06.01 2.

5. Butler M, Epstein RA, Totten A, et al. AHRQ series on complex intervention systematic reviews-Paper 3: Adapting frameworks to develop protocols. J Clin Epidemiol. 2017; PMID: 28720510. https://doi.org/10.1016/j.jclinepi.2017.06.01 3.

6. Viswanathan M, McPheeters ML, Murad $\mathrm{MH}$, et al. AHRQ series on complex intervention systematic reviews-Paper 4: Selecting Analytic Approaches. J Clin Epidemiol. 2017; PMID: 28720515. https://doi.org/10.1016/j.jclinepi.2017.06.01 4.
7. Pigott T, Noyes J, Umscheid CA, et al. AHRQ series on complex intervention systematic reviews-Paper 5: Advanced Analytic Methods. J Clin Epidemiol. 2017; PMID: 28720512. https://doi.org/10.1016/j.jclinepi.2017.06.01 5.

8. Guise J-M, Butler ME, Chang C, et al. AHRQ series on complex intervention systematic reviews-Paper 6: PRISMA-CI Extension Statement \& Checklist. J Clin Epidemiol. 2017; PMID: 28720516. https://doi.org/10.1016/j.jclinepi.2017.06.01 6.

9. Guise J-M, Butler M, Chang C, et al. AHRQ series on complex intervention systematic reviews-Paper 7: PRISMA-CI Elaboration \& Explanation. J Clin Epidemiol. 2017; PMID: 28720513. https://doi.org/10.1016/j.jclinepi.2017.06.01 7.

10. Hartling L, Guise J-M, Hempel S, et al. Fit for purpose: perspectives on rapid reviews from end-user interviews. Syst Rev. 2017;6(1):32. PMID: 28212677. https://doi.org/10.1186/s13643-017-0425-7.

11. Lavis JN, Wilson MG, Grimshaw JM, et al. Supporting the use of health technology assessments in policy making about health systems. Int J Technol Assess Health Care. 2010;26(4):405-14. PMID: 26362086. https://doi.org/10.1016/j.healthpol.2015.08.0 11.

12. Wallace BC, Small K, Brodley CE, et al. Deploying an interactive machine learning system in an evidence-based practice center: abstrackr. Proceedings of the 2nd ACM SIGHIT International Health Informatics Symposium. 2012:819-24. https://doi.org/10.1145/2110363.2110464.

13. Makkar SR, Williamson A, Turner T, et al. Using conjoint analysis to develop a system of scoring policymakers' use of research in policy and program development. Health Res Policy Syst. 2015;13:35. PMID: 26238566. https://doi.org/10.1186/s12961015-0022-y. 
14. Ølholm AM, Kidholm K, Birk-Olsen M, et al. Hospital Managers' Need for Information on Health Technology Investments. Int J Technol Assess Health Care. 2015;31(6):414-25. PMID: 26875930. https://doi.org/10.1017/S026646231500066 5.

15. Kidholm K, Olholm AM, Birk-Olsen M, et al. Hospital managers' need for information in decision-making--An interview study in nine European countries. Health Policy. 2015;119(11):1424-32. PMID: 26362086. https://doi.org/10.1016/j.healthpol.2015.08.0 11.

16. Goodman C. HTA 101: Introduction to Health Technology Assessment. Bethesda, MD: National Library of Medicine (US). 2004..

17. Luce BR, Brown RE. The use of technology assessment by hospitals, health maintenance organizations, and third-party payers in the United States. Int J Technol Assess Health Care. 1995;11(1):79-92. PMID: 7706016.

18. Jayakumar KL, Lavenberg JA, Mitchell MD, et al. Evidence synthesis activities of a hospital evidence-based practice center and impact on hospital decision making. J Hosp Med. 2016;11(3):185-92. PMID: 26505618. https://doi.org/10.1002/jhm.2498.

19. Umscheid CA, Williams K, Brennan PJ. Hospital-based comparative effectiveness centers: translating research into practice to improve the quality, safety and value of patient care. J Gen Intern Med. 2010;25(12):1352-5. PMID: 20697961. https://doi.org/10.1007/s11606-010-1476-9.

20. Gallego G, Fowler S, van Gool K. Decision makers' perceptions of health technology decision making and priority setting at the institutional level. Aust Health Rev. 2008;32(3):520-7. PMID: 20387326.

21. Gagnon M-P, Desmartis M, Poder T, et al. Effects and repercussions of local/hospitalbased health technology assessment (HTA): a systematic review. Syst Rev. 2014;3(1):129. PMID: 25352182. https://doi.org/10.1186/2046-4053-3-129.
22. Mitchell MD, Williams K, Kuntz G, et al. When the decision is what to decide: using evidence inventory reports to focus health technology assessments. Int J Technol Assess Health Care. 2011;27(2):127-32. PMID: 21450127. https://doi.org/10.1017/S026646231100003 1.

23. Gutowski C, Maa J, Hoo KS, et al. Health technology assessment at the University of California-San Francisco. J Healthc Manag. 2011;56(1):15-30. PMID: 21323025.

24. Barbieri M, Hawkins N, Sculpher M. Who does the numbers? The role of third-party technology assessment to inform health systems' decision-making about the funding of health technologies. Value Health 2009;12(2):193-201. PMID: 18700865. https://doi.org/10.1111/j.15244733.2008.00441.x.

25. Harris C, Green S, Ramsey W, et al. Sustainability in Health care by Allocating Resources Effectively (SHARE) 1: Introducing a series of papers reporting an investigation of disinvestment in a local healthcare setting. BMC Health Serv Res 2017;17(1):323. PMID: 28472962. https://doi.org/10.1186/s12913-017-2210-7.

26. Crites GE, McNamara MC, Akl EA, et al. Evidence in the learning organization. Health Res Policy Syst. 2009;7:4. https://doi.org/10.1186/1478-4505-7-4.

27. Byrne MM, Charns MP, Parker VA, et al. The effects of organization on medical utilization: an analysis of service line organization. Med Care. 2004:28-37. PMID: 14713737. https://doi.org/10.1097/01.mlr.0000102493. 28759.71.

28. Peterson K, Floyd N, Ferguson L, et al. User survey finds rapid evidence reviews increased uptake of evidence by Veterans Health Administration leadership to inform fast-paced health-system decision-making. Syst Rev. 2016;5(1):132. PMID: 27491354. https://doi.org/10.1186/s13643-016-0306-5. 
29. Xie F, Bowen JM, Sutherland SC, et al. Using health technology assessment to support evidence-based decision-making in Canada: an academic perspective. Expert Rev Pharmacoecon Outcomes Res. 2011;11(5):513-21. PMID: 21958096. https://doi.org/10.1586/erp.11.60.

30. Smith N, Mitton C, Peacock S, et al. Identifying research priorities for health care priority setting: a collaborative effort between managers and researchers. BMC Health Serv Res. 2009;9:165. PMID: 19754969. https://doi.org/10.1186/14726963-9-165.

31. Cumpston MS, Tavender EJ, Buchan HA, et al. Australian health policy makers' priorities for research synthesis: a survey. Aust Health Rev. 2012;36(4):401-11. PMID: 22951094. https://doi.org/10.1071/AH11064.

32. Gurtner S. Making the right decisions about new technologies: a perspective on criteria and preferences in hospitals. Health care Manage Rev. 2014;39(3):245-54. PMID: 23727787. https://doi.org/10.1097/HMR.0b013e318299 3b91.

33. Hartling L, Guise J-M, Kato E, et al. A taxonomy of rapid reviews links report types and methods to specific decision-making contexts. J Clin Epidemiol. 2015;68(12):1451-62.e3. PMID: 26278023. https://doi.org/10.1016/j.jclinepi.2015.05.03 6.

34. Villa L, Warholak TL, Hines LE, et al. Health care decision makers' use of comparative effectiveness research: report from a series of focus groups. J Manag Care Pharm. 2013;19(9):745-54. PMID: 24156643. https://doi.org/10.18553/jmcp.2013.19.9.745

35. Wye L, Brangan E, Cameron A, et al. Evidence based policy making and the 'art' of commissioning - how English healthcare commissioners access and use information and academic research in 'real life' decisionmaking: an empirical qualitative study. BMC Health Serv Res. 2015;15:430. PMID: 26416368. https://doi.org/10.1186/s12913015-1091-X.
36. Parker LE, Ritchie MJ, Kirchner JE, et al. Balancing health care evidence and art to meet clinical needs: policymakers' perspectives. J Eval Clin Pract. 2009;15(6):970-5. PMID: 20367694. https://doi.org/10.1111/j.13652753.2009.01209.x.

37. Alonso-Coello P, Schünemann HJ, Moberg J, et al. GRADE Evidence to Decision (EtD) frameworks: a systematic and transparent approach to making well informed healthcare choices. 1: Introduction. BMJ. 2016;353:i2016. PMID: 27353417. https://doi.org/10.1136/bmj.i2016.

38. Moat KA, Lavis JN, Wilson MG, et al. Twelve myths about systematic reviews for health system policymaking rebutted. J Health Serv Res Policy. 2013;18(1):44-50. PMID: 23393042. https://doi.org/10.1258/jhsrp.2012.011175.

39. Gagnon M-P, Attieh R, Ghandour EK, et al. A systematic review of instruments to assess organizational readiness for knowledge translation in health care. PLoS One. 2014;9(12):e114338. PMID: 25474622. https://doi.org/10.1371/journal.pone.011433 8.

40. Catallo C, Sidani S. The Self-assessment for Organizational Capacity Instrument for evidence-informed health policy: preliminary reliability and validity of an instrument. Worldviews Evid Based Nurs. 2014;11(1):35-45. PMID: 24127906. https://doi.org/10.1111/wvn.12018.

41. Lefebre N. Knowledge to action: integrating the use of evidence in management decision making. Healthc Manage Forum. 2010;23(2):48-57. PMID: 21739839. https://doi.org/10.1016/j.hcmf.2010.04.005.

42. Gifford W, Lefebre N, Davies B. An organizational intervention to influence evidence-informed decision making in home health nursing. J Nurs Adm. 2014;44(7/8):395-402. PMID: 25072229. https://doi.org/10.1097/NNA.000000000000 0089. 
43. Perrier L, Mrklas K, Lavis JN, et al. Interventions encouraging the use of systematic reviews by health policymakers and managers: a systematic review. Implement Sci. 2011;6(1):43. PMID: 21524292. https://doi.org/10.1186/17485908-6-43.

44. Dobbins M, Hanna SE, Ciliska D, et al. A randomized controlled trial evaluating the impact of knowledge translation and exchange strategies. Implement Sci. 2009;4(1):61. PMID: 19775439. https://doi.org/10.1186/1748-5908-4-61.

45. Ellen ME, Lavis JN, Sharon A, et al. Health systems and policy research evidence in health policy making in Israel: what are researchers' practices in transferring knowledge to policy makers? Health Res Policy Syst. 2014;12:67. PMID: 25491890. https://doi.org/10.1186/1478-4505-12-67.

46. Ellen ME, Leon G, Bouchard G, et al. Barriers, facilitators and views about next steps to implementing supports for evidence-informed decision-making in health systems: a qualitative study. Implement Sci. 2014;9:179. PMID: 25476735. https://doi.org/10.1186/s13012014-0179-8.

47. Ellen ME, Leon G, Bouchard G, et al. What supports do health system organizations have in place to facilitate evidence-informed decision-making? A qualitative study. Implement Sci. 2013;8:84. PMID: 23915278. https://doi.org/10.1186/17485908-8-84.

48. Innis J, Dryden-Palmer K, Perreira T, et al. How do health care organizations take on best practices? A scoping literature review. Int J Evid Based Healthc. 2015;13(4):25472. PMID: 26134546. https://doi.org/10.1097/XEB.000000000000 0049.

49. Petkovic J, Welch V, Jacob MH, et al. The effectiveness of evidence summaries on health policymakers and health system managers use of evidence from systematic reviews: a systematic review. Implement Sci. 2016;11(1):162. PMID: 27938409 https://doi.org/10.1186/s13012-016-0530-3.
50. Murthy L, Shepperd S, Clarke MJ, et al. Interventions to improve the use of systematic reviews in decision-making by health system managers, policy makers and clinicians. Cochrane Database Syst Rev. 2012; PMID: 22972142. https://doi.org/10.1002/14651858.CD00940 1.pub2.

51. Aicken CRH, Armstrong NT, Cassell JA, et al. Barriers and opportunities for evidencebased health service planning: the example of developing a Decision Analytic Model to plan services for sexually transmitted infections in the UK. BMC Health Serv Res. 2012;12:202. PMID: 22805183. https://doi.org/10.1186/1472-6963-12-202.

52. Goetghebeur MM, Wagner M, Khoury H, et al. Evidence and Value: Impact on DEcisionMaking--the EVIDEM framework and potential applications. BMC Health Serv Res. 2008;8:270. PMID: 19102752 https://doi.org/10.1186/1472-6963-8-270.

53. Munn SR. Hospital-based health technology assessment: insights from New Zealand. PharmacoEconomics. 2014;32(9):815-7. PMID: 25117205 https://doi.org/10.1007/s40273-014-0202-6.

54. Chambers DA, Feero WG, Khoury MJ. Convergence of Implementation Science, Precision Medicine, and the Learning Health Care System: A New Model for Biomedical Research. JAMA. 2016;315(18):1941-2. PMID: 27163980. https://doi.org/10.1001/jama.2016.3867.

55. Insitute of Medicine. Engineering a learning healthcare system: A look at the future: Workshop summary: Washington, DC: National Academies Press; 2011.

56. Mitchell MD, Williams K, Brennan PJ, et al. Integrating local data into hospital-based healthcare technology assessment: two case studies. Int J Technol Assess Health Care. 2010;26(3):294-300. PMID: 20584358. https://doi.org/10.1017/S026646231000033 4.

57. Fleming C. Berwick brings the 'Triple Aim'to CMS. Health Affairs Blog. http://healthaffairs.org/blog/2010/09/1 4/berwickbrings-the-triple-aim-to-cms/ 2015;15. Accessed April, 2017. 
58. Insitute of Medicine. Integrating Research and Practice: Health System Leaders Working Toward High-Value Care: Workshop Summary. Washington, DC: National Academies Press; 2015.PMID: 25834870 .

59. Norris SL, Atkins D, Bruening W, et al. Observational studies in systemic reviews of comparative effectiveness: AHRQ and the Effective Health Care Program. J Clin Epidemiol. 2011;64(11):1178-86. PMID: 21636246. https://doi.org/10.1016/j.jclinepi.2010.04.02 7.

60. Murad MH, Almasri J, Alsawas M, et al. Grading the quality of evidence in complex interventions: a guide for evidence-based practitioners. Evid based Med. 2017;22(1):20-2. PMID: 27932400. https://doi.org/10.1136/ebmed-2016110577.

61. Murad MH, Mustafa RA, Schünemann HJ, et al. Rating the certainty in evidence in the absence of a single estimate of effect. Evid Based Med. 2017:ebmed-2017-110668. PMID: 28320705. https://doi.org/10.1136/ebmed-2017110668.

62. Carter BJ. Evidence-based decision-making: practical issues in the appraisal of evidence to inform policy and practice. Aust Health Rev. 2010;34(4):435-40. PMID: 21108904. https://doi.org/10.1071/AH09778.

63. Lewis S. Toward a general theory of indifference to research-based evidence. J Health Serv Res Policy. 2007;12(3):166-72. PMID: 17716420. https://doi.org/10.1258/13558190778154309 4.

64. Harris C, Allen K, Waller C, et al. Sustainability in Health care by Allocating Resources Effectively (SHARE) 5: developing a model for evidence-driven resource allocation in a local healthcare setting. BMC Health Serv Res. 2017;17(1):342. PMID: 28486973. https://doi.org/10.1186/s12913-017-2208-1.
65. Harris C, Allen K, Waller C, et al. Sustainability in Health care by Allocating Resources Effectively (SHARE) 7: Supporting staff in evidence-based decisionmaking, implementation and evaluation in a local healthcare setting. BMC Health Serv Res. 2017;17(1):430. PMID: 28637473. https://doi.org/10.1186/s12913-017-2388-8.

66. Insitute of Medicine. Best care at lower cost: the path to continuously learning health care in America:: Washington, DC: National Academies Press; 2013.

67. Bindman AB. The Agency for Healthcare Research and Quality and the Development of a Learning Health Care System. JAMA Intern Med. 2017; PMID: 28542694. https://doi.org/10.1001/jamainternmed.2017. 2589.

68. Bambra C, Joyce KE, Bellis MA, et al. Reducing health inequalities in priority public health conditions: using rapid review to develop proposals for evidence-based policy. J of Public Health (Oxf). 2010;32(4):496-505. PMID: 20435581. https://doi.org/10.1093/pubmed/fdq028.

69. Jackson GL, Zullig LL, Zafar SY, et al. Using NCCN clinical practice guidelines in oncology to measure the quality of colorectal cancer care in the veterans health administration. J Natl Compr Canc Netw. 2013;11(4):431-41. PMID: 23584346.

70. Moat KA, Lavis JN. 10 best resources for ... evidence-informed health policy making. Health Policy and Plan. 2013;28(2):215-8. PMID: 22717501. https://doi.org/10.1093/heapol/czs050.

71. Wilson MG, Moat KA, Lavis JN. The global stock of research evidence relevant to health systems policymaking. Health Res Policy Syst. 2013;11:32. PMID: 24007378. https://doi.org/10.1186/1478-4505-11-32.

72. Wilson MG, Lavis JN, Gauvin F-P. Developing a rapid-response program for health system decision-makers in Canada: findings from an issue brief and stakeholder dialogue. Syst Rev. 2015;4:25. PMID: 25875495. https://doi.org/10.1186/s13643015-0009-3. 
73. Lavis JN, Permanand G, Oxman AD, et al. SUPPORT Tools for evidence-informed health Policymaking (STP) 13: Preparing and using policy breifs to support evidenceinformed policymaking. Health Res Policy Syst. 2009(7(Suppl1):S13); PMID: 20018103. https://doi.org/10.1186/14784505-7-S1-S13.

74. Anonymous. Becoming a meaningful user of health IT. Hosp Health Netw. 2010;84(12):48-58. PMID: 21268505.

75. Boyko JA. Evidence-informed health policy making in Canada: past, present, and future. J Evid based Med. 2015;8(4):215-21. PMID: 26275217. https://doi.org/10.1111/jebm.12169.

76. Goeree R, Levin L, Chandra K, et al. Health technology assessment and primary data collection for reducing uncertainty in decision making. J Am Coll Radiol. 2009;6(5):332-42. PMID: 19394574. https://doi.org/10.1016/j.jacr.2009.01.012.

77. Lavis JN, Wilson MG, Moat KA, et al. Developing and refining the methods for a 'one-stop shop'for research evidence about health systems. Health Res Policy Syst. 2015;13(1):10. PMID: 25971248. https://doi.org/10.1186/1478-4505-13-10.

78. Ritrovato M, Faggiano FC, Tedesco G, et al. Decision-Oriented Health Technology Assessment: One Step Forward in Supporting the Decision-Making Process in Hospitals. Value Health. 2015;18(4):505-11. PMID: 26091605. https://doi.org/10.1016/j.jval.2015.02.002.

79. Williams B, Perillo S, Brown T. What are the factors of organisational culture in health care settings that act as barriers to the implementation of evidence-based practice? A scoping review. Nurse Educ Today. 2015;35(2):e34-e41. PMID: 25482849. https://doi.org/10.1016/j.nedt.2014.11.012. 


\title{
Appendix A. Search Strategy
}

\section{Ovid MEDLINE(R) Epub Ahead of Print, In-Process \& Other Non-Indexed Citations, Ovid MEDLINE(R) Daily and Ovid MEDLINE(R) 1946 to Present}

\author{
Date Searched: April 7, 2017
}

Searched by: Robin Paynter, MLIS

\begin{tabular}{|c|c|c|}
\hline 1 & $\begin{array}{l}\text { "Decision Making, Organizational"/ or *Decision Support Techniques/ or "Delivery of Health Care"/ or } \\
\text { "Delivery of Health Care, Integrated"/ or *Diffusion of Innovation/ or *Efficiency, Organizational/ or } \\
\text { *Health Policy/ or *Health Planning/ or *Health Priorities/ or *"Models, Organizational"/ or } \\
\text { *Organizational Culture/ or *Organizational Innovation/ or *Organizational Objectives/ or *Organizational } \\
\text { Policy/ or *"Outcome Assessment (Health Care)"/ or *Planning Techniques/ or *"Process Assessment } \\
\text { (Health Care)"/ or Quality Improvement/ or "Quality Indicators, Health Care"/ or Value-Based } \\
\text { Purchasing/ }\end{array}$ & 228308 \\
\hline 2 & $\begin{array}{l}\text { Academic Medical Centers/mt, og or Accountable Care Organizations/mt, og or *Chief Executive } \\
\text { Officers, Hospital/ or *Health Facility Administration/ or *Health Facility Administrators/ or Health } \\
\text { Services/mt, og or Health Services Administration/ or *Health Systems Agencies/ or *Hospital } \\
\text { Administration/ or *Hospital Administrators/ or exp *Hospitals/mt, og or *"Organization and } \\
\text { Administration"/ or *Policy Making/ or Provider-Sponsored Organizations/mt, og or (administrat* or } \\
\text { leader* or manager* or decision-making or decisionmaking or decision-maker* or policymaking or } \\
\text { policymaker* or policy-maker* or learning-health*).ti,kf. }\end{array}$ & 258945 \\
\hline 3 & $\begin{array}{l}\text { Meta-Analysis as Topic/ or Review Literature as Topic/ or Health Services Research/ or Technology } \\
\text { Assessment, Biomedical/ or Cost-Benefit Analysis/ or Evidence-Based Medicine/ or Evidence-Based } \\
\text { Practice/ or "Practice Guidelines as Topic"/ or Guidelines as Topic/ or (guideline* or review* or synthes* } \\
\text { or meta-analys* or evidence* or HTA* or technology assessment* or implement* or facilitator* or barrier* } \\
\text { or "information need*").ti,kf. }\end{array}$ & 1288836 \\
\hline 4 & and/1-3 & 3748 \\
\hline 5 & 4 not Shared Decision-Making.ti,kf. & 3675 \\
\hline 6 & limit 5 to (english language and yr="2007 -Current") & 1553 \\
\hline
\end{tabular}




\section{Appendix B. Initial Framework}

\section{Figure B-1. Preliminary framework for understanding evidence needs of health systems}

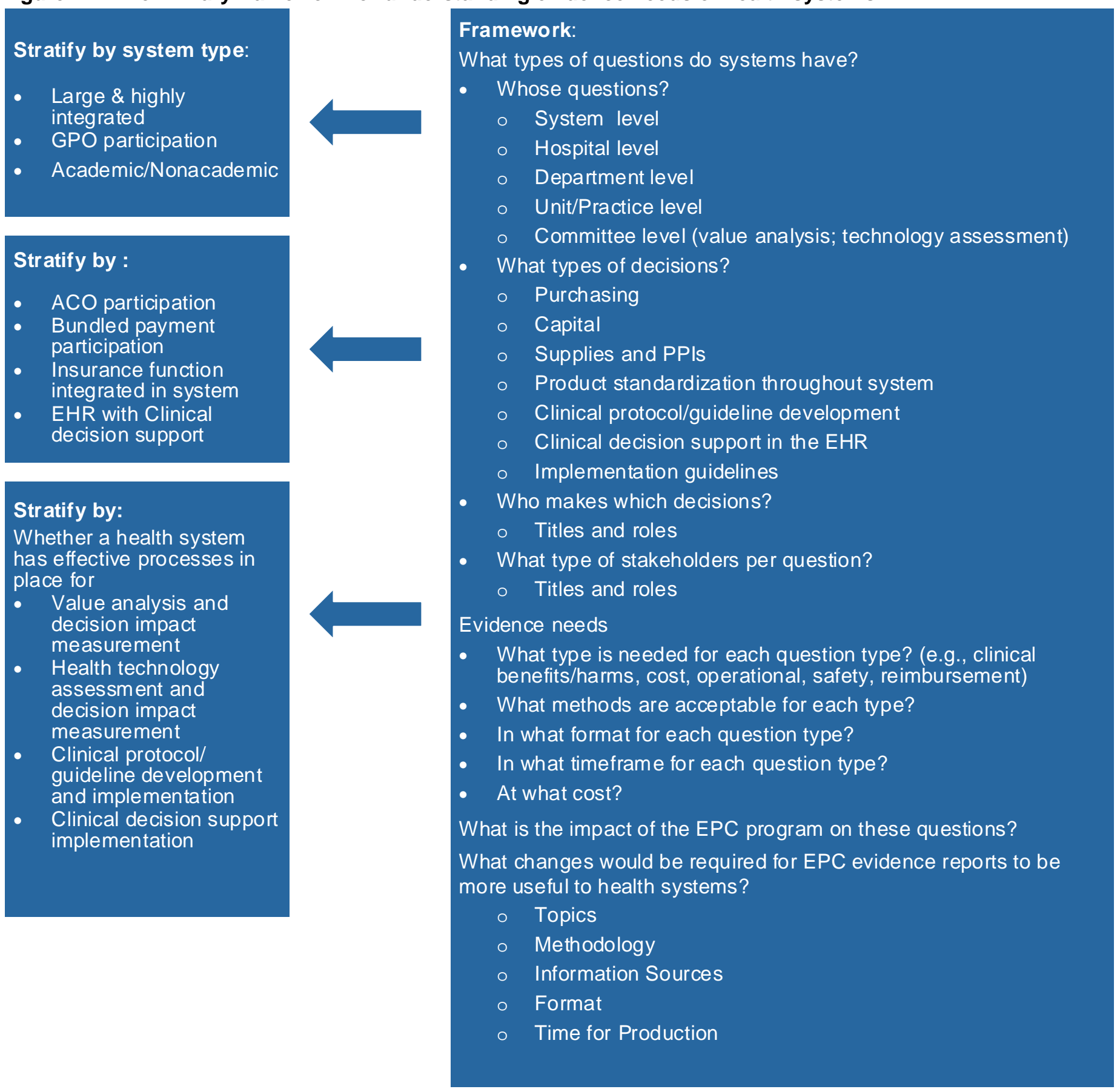

ACO=accountable care organization; EHR=electronic health record; EPC=evidence-based practice center; GPO=group purchasing organization; $\mathrm{PPI}=$ physician preference items 


\section{Appendix C. Evidence Tables}

\begin{tabular}{|c|c|c|}
\hline First Author, Year & Setting & Findings \\
\hline Bambra $2010^{68}$ & $\begin{array}{l}\text { UK public health } \\
\text { system }\end{array}$ & $\begin{array}{l}\text { Rapid narrative reviews followed by consensus process } \\
\text { How to address inequalities/disparities in public health } \\
\text { initiatives }\end{array}$ \\
\hline Barbieri $2009^{24}$ & UK & $\begin{array}{l}\text { Descriptive study comparing different HTA processes } \\
\text { - Identify appropriate comparators and patient subgroups } \\
\text { relevant to the health system } \\
\text { - Independent assessment of manufacturer claims }\end{array}$ \\
\hline Chambers $2016^{54}$ & U.S. & $\begin{array}{l}\text { Commentary: notes need for evidence to inform precision medicine } \\
\text { initiatives and implementation strategies in learning healthcare systems }\end{array}$ \\
\hline Crites $2009^{26}$ & $\begin{array}{l}\text { U.S. (academic } \\
\text { medical centers) }\end{array}$ & $\begin{array}{l}\text { Framework (review and consensus) } \\
\text { - Patient care decisions } \\
\text { - } \quad \text { Deck process decisions } \\
\end{array}$ \\
\hline Cumpston $2012^{31}$ & Australia & $\begin{array}{l}\text { Source: Annual reports } \\
\text { - hospital demand management } \\
\text { - } \text { - } \text { corkfy and quality of hospital care recruitment and organization } \\
\text { - } \quad \text { illness) } \\
\text { rural service delivery } \\
\text { - native peoples' health } \\
\text { Source: Survey of policymakers (after excluding topics on single } \\
\text { conditions) }\end{array}$ \\
\hline
\end{tabular}

- Professional interventions - clinical networks' impact on quality outcomes

- Financial

o Provider focus - effects of funding models on quality and access in rural settings; financial incentives impact on hospital performance; regional vs. national management of health budgets impact on efficiency/effectiveness

- Organizational interventions

o Provider oriented-advance practice roles (paramedics, rapid response teams, allied health), hospitalists; recruiting minorities into health workforce; workplace safety; support to providers in rural areas, use of locum tenens staff; interventions to improve cultural appropriateness;

o Patient-oriented - interventions to improve access for prisoners, refugees; appropriate follow up to screening tests; community engagement in health service planning and delivery

o Structural interventions - predicting demand, determining health priorities for population health; interventions to improve planning for workforce needs; care coordination

o Regulatory - effects of credentialing of health professionals on safety and quality; coordination of across payment systems 


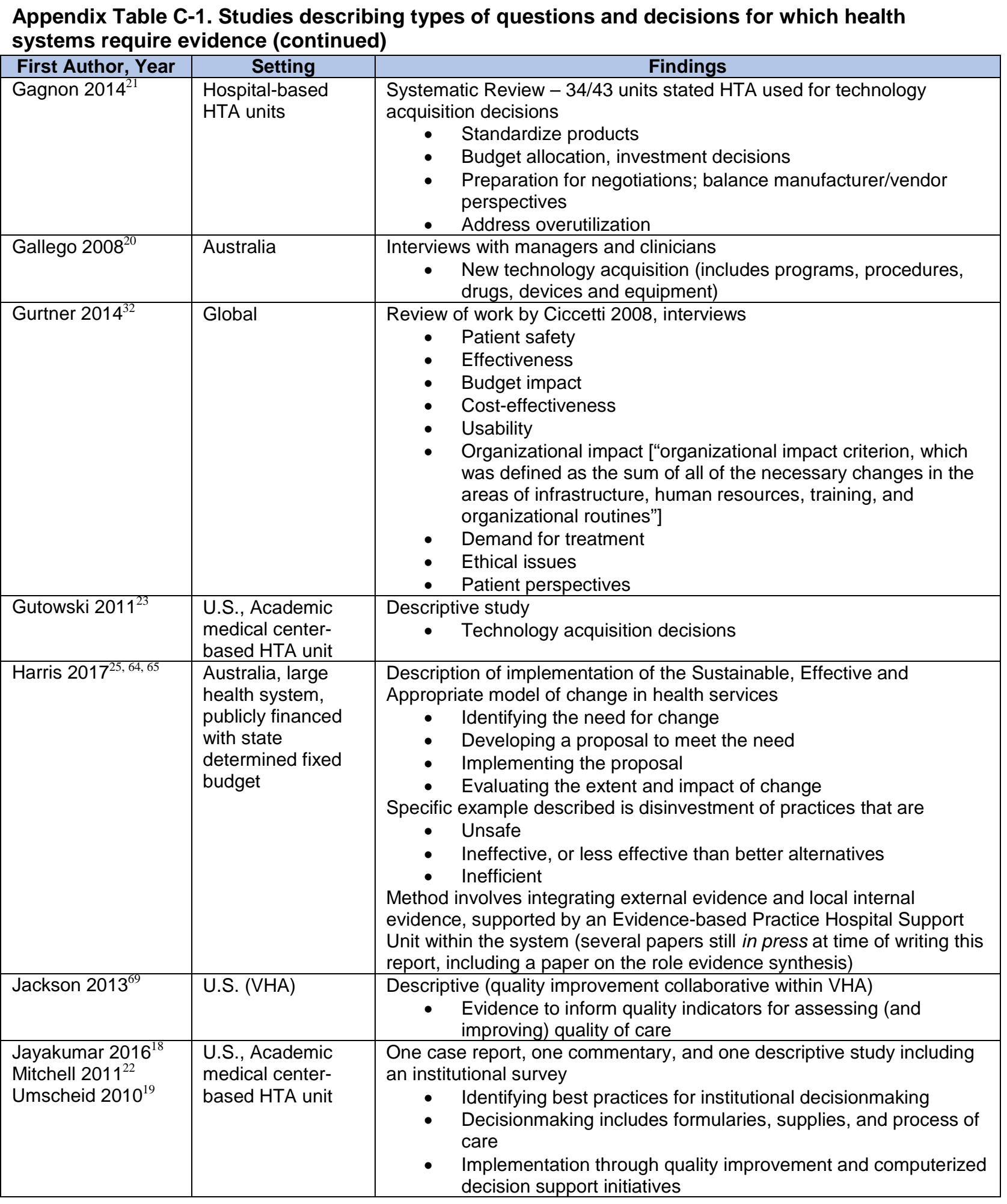


Appendix Table C-1. Studies describing types of questions and decisions for which health systems require evidence (continued)

\begin{tabular}{|c|c|c|}
\hline First Author, Year & Setting & $\begin{array}{ll} & \text { Findings } \\
\end{array}$ \\
\hline Kidholm $2015^{15}$ & Europe & $\begin{array}{ll}\text { Interviews with hospital managers: } \\
\text { - } \\
\text { - } & \text { Econominics } \\
\text { - } & \text { Safety } \\
\text { - } & \text { Health problems } \\
\text { - } & \text { Organizational aspects } \\
\text { - } & \text { Political and strategic information } \\
\text { - } & \text { Ethics } \\
\text { - } & \text { Nature of treatment } \\
\text { - } & \text { Social aspects } \\
\text { - } & \text { Legal information }\end{array}$ \\
\hline Lavis $2010^{11}$ & $\begin{array}{l}\text { Canada, Europe, } \\
\text { U.S. }\end{array}$ & $\begin{array}{l}\text { Review of } 223 \text { HTAs from agencies in Canada, Europe and U.S. serving } \\
\text { different health system levels (national, provincial and organizational) } \\
\text { - } \quad \text { Topics to inform policymaking within health systems: "which } \\
\text { programs, services, drugs and devices to fund" } \\
\text { - Topics to inform policymaking about health systems: } \\
\text { "governance, financial and delivery arrangements within which } \\
\text { clinical [and public health] programs and services are provided" } \\
\text { - Assessments of local professional, social, political, legal and } \\
\text { - } \quad \text { ethical considerations } \\
\text { Context-specific actionable messages }\end{array}$ \\
\hline $\begin{array}{l}\text { Luce and Brown } \\
1995^{17}\end{array}$ & $\begin{array}{l}\text { U.S., Hospitals, } \\
\text { Hospital systems, } \\
\text { Health } \\
\text { Maintenance } \\
\text { Organizations, } \\
\text { Group Purchasing } \\
\text { Organizations, } \\
\text { Public and private } \\
\text { payers }\end{array}$ & $\begin{array}{l}\text { Survey of hospitals, HMOs, public and private payers, GPOs } \\
\text { - Purchasing } \\
\text { - } \text { Controlling costs } \\
\text { - } \text { Marketing } \\
\text { - } \text { Coveraing early obsolescence } \\
\text { - Determining appropriate/standard care }\end{array}$ \\
\hline $\begin{array}{l}\text { Luce and Brown } \\
1995^{17} \text { (continued) }\end{array}$ & U.S. & $\begin{array}{l}\text { Topics selected based on } \\
\text { - } \quad \text { Cost } \\
\text { - } \quad \text { Sarketing } \\
\text { - } \quad \text { Legal defense (coverage appeals) } \\
\text { - Provider demands } \\
\text { - } \quad \text { Patient requests } \\
\text { - Legislative activities }\end{array}$ \\
\hline Makkar $2015^{13}$ & Australia & $\begin{array}{l}\text { Framework for use of evidence; identified categories of decisions for } \\
\text { which evidence is relevant (using self-assessment instrument and } \\
\text { conjoint analysis) } \\
\text { - What issues should we prioritize and what actions should we } \\
\text { - } \quad \text { Whake to address identified issues? } \\
\text { clarify thinking about an issue? } \\
\text { - How can we gain support for decisions already made? } \\
\text { - How can we respond to organizational or legislative } \\
\text { requirements? }\end{array}$ \\
\hline $\begin{array}{l}\text { Moat } 2013,{ }^{70} \text { Wilson } \\
2013 ;{ }^{71} \text { Lavis } 2015^{72}\end{array}$ & Canada & $\begin{array}{l}\text { Topics cataloged for the Health Systems Evidence Web site: } \\
\text { - Delivery arrangements } \\
\text { - Implementing change } \\
\text { - } \quad \text { Governance } \\
\text { - Financial arrangements }\end{array}$ \\
\hline
\end{tabular}


Appendix Table C-1. Studies describing types of questions and decisions for which health systems require evidence (continued)

\begin{tabular}{|c|c|c|}
\hline First Author, Year & Setting & Findings \\
\hline Ølhom $2015^{14}$ & Europe & $\begin{array}{l}\text { Systematic review of studies of information needs of hospital managers } \\
\text { (informed questions for Kidholm } 2015 \text { interviews) } \\
\text { - Political and strategic } \\
\text { - Clinical effectiveness } \\
\text { - } \quad \text { Organizational } \\
\text { - } \quad \text { Health problems and use of technology } \\
\text { - Technical characteristics of technologies } \\
\text { - } \quad \text { Ethical }\end{array}$ \\
\hline Parker $2009^{36}$ & U.S. & $\begin{array}{l}\text { Interviews with VHA executive level policymakers and their staff } \\
\text { suggested need for other types of evidence beyond randomized trials, } \\
\text { such as case studies and patient preference studies. }\end{array}$ \\
\hline Peterson $2016^{28}$ & U.S. VHA & $\begin{array}{l}\text { Survey of VHA leaders on their use of Evidence Synthesis Program's } \\
\text { Rapid Reviews on policy or organizational and managerial system topics } \\
\text { or process of care topics: } \\
\text { - Responding to regulatory and policy directives } \\
\text { - Developing and evaluating programs } \\
\text { - Determining implementation strategies } \\
\text { Identifying future research needs }\end{array}$ \\
\hline Smith $2009^{30}$ & $\begin{array}{l}\text { Canada (British } \\
\text { Columbia) }\end{array}$ & $\begin{array}{l}\text { Forums of health care managers and researchers } \\
\text { - Deciding how to decide } \\
\text { - } \quad \text { Identify "disinvestment opportunities" } \\
\end{array}$ \\
\hline Xie $2011^{29}$ & Canada & $\begin{array}{l}\text { Perspective on HTA in Canada } \\
\quad \text { Implementing new technologies }\end{array}$ \\
\hline
\end{tabular}




\begin{tabular}{|c|c|c|}
\hline First Author, Year & Setting & Findings \\
\hline $\begin{array}{l}\text { Hartling } 2017^{10} \\
\text { Hartling } 2015^{33}\end{array}$ & U.S. & $\begin{array}{l}\text { Interviews } \\
\text { - Rapid responses, rapid reviews seen as helpful to health system } \\
\text { decisionmakers } \\
\text { - Credibility of review producers, relevance of key questions, } \\
\text { close-working relationship with producers critical to } \\
\text { decisionmakers }\end{array}$ \\
\hline Jayakumar $2016^{18}$ & U.S. & $\begin{array}{l}\text { Descriptive analysis of a hospital evidence-based practice center } \\
\text { database of rapid systematic reviews since center's inception (July 2006- } \\
\text { June 2014) and survey of report requestors from the last } 4 \text { fiscal years. }\end{array}$ \\
\hline Lavis $2009^{73}$ & Canada, Europe & $\begin{array}{l}\text { Expert perspectives -Supporting Policy Relevant Reviews and Trials } \\
\text { (SUPPORT) } \\
\text { - Developing policy briefs to inform policy deliberations }\end{array}$ \\
\hline Lavis $2010^{11}$ & & $\begin{array}{l}\text { Interviews } \\
\text { - "Graded entry" to the health technology assessment - key } \\
\text { messages needed for decisionmaking, short plain-language } \\
\text { summary; prominent headings to make it easier to scan for } \\
\text { information } \\
\text { - Followed by brief executive summary including benefits, harms } \\
\text { - } \quad \text { Fosts, uncertainty, subgroup information; applicability information } \\
\text { report available if necessary) }\end{array}$ \\
\hline Mitchell $2011^{22}$ & $\begin{array}{l}\text { U.S., Academic } \\
\text { medical center- } \\
\text { based HTA unit }\end{array}$ & $\begin{array}{l}\text { Descriptive study } \\
\text { - Evidence inventories/rapid reviews produced internally or using } \\
\text { external sources }\end{array}$ \\
\hline Murthy $2012^{50}$ & Canada, Europe & $\begin{array}{l}\text { Systematic review: } \\
\text { D Distribution of bulletins based on systematic reviews associated } \\
\text { with practice improvement }\end{array}$ \\
\hline Peterson $2016^{28}$ & U.S. (VHA) & $\begin{array}{l}\text { Survey of VHA leaders on their use of Evidence Synthesis Program's } \\
\text { Rapid Reviews on policy or organizational and managerial system topics } \\
\text { or process of care topics: } \\
\text { - High level of agreement that the reviews influenced the delivery } \\
\text { system } \\
\text { - High level of agreement that reviews placed the evidence in } \\
\text { context for the VA system }\end{array}$ \\
\hline Petkovic $2016^{49}$ & $\begin{array}{l}\text { Canada, Europe, } \\
\text { U.S., Africa, Asia }\end{array}$ & $\begin{array}{l}\text { Systematic review of studies of derivative products from systematic } \\
\text { reviews for policymakers and managers } \\
\text { - Two studies assessed the use of different formats of evidence } \\
\text { summaries in decision-making and found little to no difference in } \\
\text { effect } \\
\text { - Four studies found little difference in effect of different summary } \\
\text { products for knowledge, understanding or beliefs } \\
\text { - Three studies found not difference in usefulness or usability } \\
\text { Summary of findings tables were easier to understand compared } \\
\text { to complete systematic reviews. Participants preferred tables } \\
\text { including study event rates and absolute differences }\end{array}$ \\
\hline Wye $2015^{35}$ & UK & $\begin{array}{l}\text { Interviews, observation of policymakers: } \\
\text { - } \quad \text { Preferred verbal presentation; } \\
\text { - } \quad \text { Preferedred inclusion of local information; } \\
\text { Pimplified and brief documents }\end{array}$ \\
\hline
\end{tabular}




\begin{tabular}{|c|c|c|}
\hline First Author, Year & Setting & Findings \\
\hline (Anonymous) $2010^{74}$ & U.S. & $\begin{array}{l}\text { Commercial online tool } \\
\text { - For using evidence to create locally and collaboratively } \\
\text { developed but standardized order sets }\end{array}$ \\
\hline Aicken $2012^{51}$ & U.K. & $\begin{array}{l}\text { Decision analytic modelling } \\
\text { - At the local level for decisions about service delivery }\end{array}$ \\
\hline Boyko $2015^{75}$ & Canada & $\begin{array}{l}\text { Review of Evidence Informed Health Policymaking (EIHP) in Canada } \\
\text { (uses language from Ellen framework below) } \\
\text { - Examples of "push" efforts } \\
\text { - Examples of "pull" efforts } \\
\text { - Examples of "linkage and exchange" efforts }\end{array}$ \\
\hline Catallo $2014^{40}$ & Canada & $\begin{array}{l}\text { Psychometric study of instrument for assessing organizational } \\
\text { capacity for using evidence in decisionmaking } \\
\text { - Culture and values supporting use of research evidence in } \\
\text { - } \text { decisions } \\
\text { - } \quad \text { Abilitity to acquire research evidence (access to resources) } \\
\text { - Capacity to assess quality and applicability and to interpret } \\
\text { results } \\
\text { - Use of research evidence to inform recommendations } \\
\text { - Monitoring and evaluation of policies and programs } \\
\text { Continuing professional development on evidence-based } \\
\text { topics }\end{array}$ \\
\hline $\begin{array}{l}\text { Ellen } 2014 a,{ }^{45} \\
2014 b{ }^{46} 2013^{47}\end{array}$ & Canada & $\begin{array}{l}\text { Interviews, seven domain framework for promoting knowledge } \\
\text { translation in health system decision making } \\
\text { - Establishing a climate where research evidence is used in } \\
\text { decisionmaking } \\
0 \text { Creating formal accountability for use of evidence } \\
\text { o Include use of research evidence in decisionmaking } \\
\text { in the organization's mission, vision, values and } \\
\text { strategic planning } \\
\text { - Production of timely and relevant research by researchers } \\
\text { and funders } \\
\text {-Push" efforts by librarians or knowledge brokers to } \\
\text { - disseminate research evidence to potential users } \\
\text { "Facilitating pull" efforts by health system to ensure } \\
\text { appropriate infrastructure is in place for knowledge users to } \\
\text { - have access to research evidence } \\
\text { "Pull" efforts by health system decisionmakers to enable } \\
\text { - "Linkagriate use of evidence } \\
\text { between researchange" efforts facilitating relationships } \\
\text { - Evaluation of knowledge translation efforts } \\
\text { Barriers to use of evidence in health system decisionmaking } \\
\text { - Limited resources } \\
\text { - Time constraints } \\
\text { Facilitators } \\
\text { - Gegative attitudes toward change } \\
\text { - Two-way interest from health system decisionmakers } \\
\text { decisionmakers }\end{array}$ \\
\hline Gagnon $2014^{39}$ & Multiple & $\begin{array}{l}\text { Systematic review of instruments to assess organizational readiness } \\
\text { for knowledge translation in health care identifying } 26 \text { instruments. }\end{array}$ \\
\hline
\end{tabular}




\begin{tabular}{|c|c|c|}
\hline First Author, Year & Setting & Findings \\
\hline Gifford $2014^{42}$ & Canada & $\begin{array}{l}\text { Evaluation of organizational strategies to promote evidence informed } \\
\text { decision making by nurse managers and clinical leaders in home } \\
\text { health care. Research questions: What organizational structures and } \\
\text { processes facilitate and support EIDM by managers and clinical } \\
\text { leaders? What are the barriers and enablers to influencing EIDM? } \\
\text { - Intervention included an interactive educational workshop, } \\
\text { evidence facilitators, library services, information sharing, and } \\
\text { encouragement and recognition. } \\
\text { Participants reported having more resources to conduct } \\
\text { research, having relevant staff to contribute to EIDM, } \\
\text { receiving more feedback and rationale on decisions, and } \\
\text { being more informed about how evidence informed decision } \\
\text { making in the organization. }\end{array}$ \\
\hline Goeree $2009^{76}$ & Canada & $\begin{array}{l}\text { Description of the Ontario HTA process } \\
\text { Health care facilities, community-based health service } \\
\text { providers or the Ministry of Health and Long-Term Care } \\
\text { request the HTAs } \\
\text { - Uncertainty after HTA completion may be addressed through } \\
\text { field evaluations (similar to coverage with evidence } \\
\text { development) } \\
\text { - An economic model is developed comparing the technology } \\
\text { and alternative strategies; value of information analysis } \\
\text { performed to determine feasibility and design the field } \\
\text { evaluation study } \\
\text { - Study results placed in context with HTA (literature review) }\end{array}$ \\
\hline Goetghebeur $2008^{52}$ & Canada & $\begin{array}{l}\text { Framework for presenting evidence to facilitate decisionmaking in } \\
\text { which scientific judgments are separated from value judgments } \\
\text { - Used Multicriteria Decision Analysis (MCDA) for clarifying } \\
\text { value judgments } \\
\text { - Developed a Value Matrix encompassing quality of evidence, } \\
\text { impact on disease, economic impact (budget impact analysis) }\end{array}$ \\
\hline Innis $2015^{48}$ & U.S. & 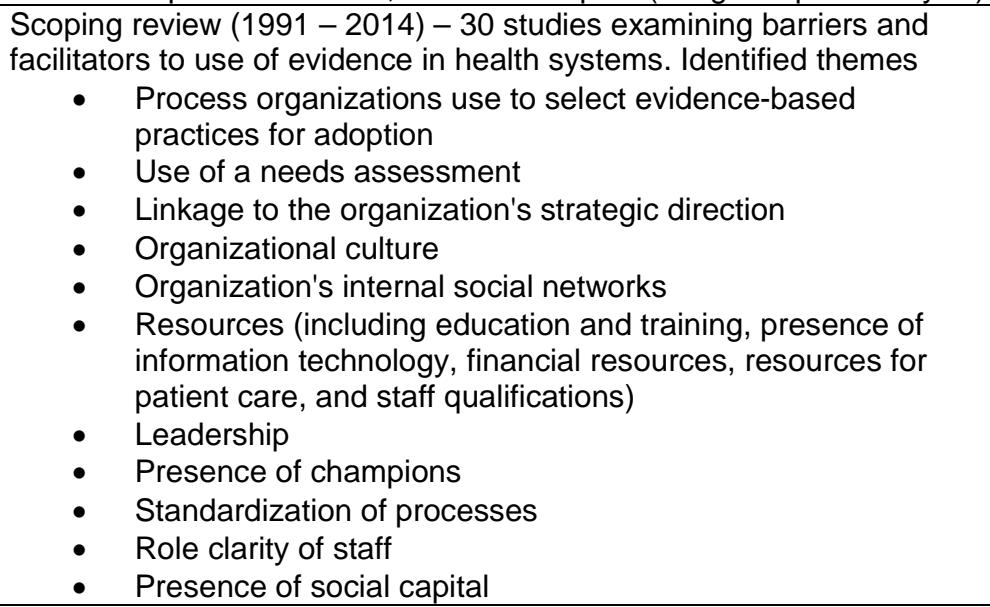 \\
\hline Lavis $2015^{77}$ & Canada & $\begin{array}{l}\text { Descriptive } \\
\text { Creation of the healthsystemsevidence.org Web site to provide health } \\
\text { systems with easy access to evidence on } \\
\text { - Governance arrangements } \\
\text { - } \text { Financial arrangements } \\
\text { - Implivery arrangements } \\
\text { - Provider types } \\
\text { - Disease areas } \\
\text { - Settings }\end{array}$ \\
\hline
\end{tabular}




\begin{tabular}{|c|c|c|}
\hline First Author, Year & Setting & $\begin{array}{rr}\text { Findings } \\
\end{array}$ \\
\hline Lefebre $2010^{41}$ & Canada & $\begin{array}{l}\text { Case study using an organizational self-assessment tool } \\
\text { - } \quad \text { Found that use of evidence in management decisionmaking } \\
\text { - } \quad \text { Bas sporadic at baseline } \\
\text { - } \quad \text { Interventions targeting barriers designed and carried out over } \\
\text { - } 18 \text { months } \\
\text { Evaluation at } 1 \text { year post-implementation showed increased } \\
\text { - } \quad \text { use of evidence } \\
\text { Provides a list of key steps for other organizations to use }\end{array}$ \\
\hline Makkar $2015^{13}$ & Australia & $\begin{array}{l}\text { Survey - used conjoint analysis to develop a framework; used the } \\
\text { Staff Assessment of enGagement with Evidence from research } \\
\text { (SAGE) and created a scoring system. } \\
\text { - Results of the assessment can assist organizations in } \\
\text { improving use of evidence }\end{array}$ \\
\hline Munn $2014^{53}$ & New Zealand & $\begin{array}{l}\text { Description of scoring method } \\
\text { - Using HTA and cost information with input from local } \\
\text { stakeholders about expected changes in outcomes and costs } \\
\text { with alternative choices }\end{array}$ \\
\hline Perrier $2011^{43}$ & Canada & $\begin{array}{l}\text { Systematic review identified a single cross-sectional study in } 3 \\
\text { publications and one RCT (Dobbins 2009) examining interventions to } \\
\text { increase use of systematic reviews in decisionmaking. } \\
\text { - The strength of evidence was judged to be weak for } \\
\text { determining whether any of the interventions were effective } \\
\text { (access to a repository; repository plus tailored messages; } \\
\text { repository, tailored messages and a "knowledge broker") }\end{array}$ \\
\hline Ritrovato $2015^{78}$ & Europe & $\begin{array}{l}\text { "Decision-oriented HTA" } \\
\bullet \quad \text { Integrates multi-criteria decision analysis (MCDA) into HTA } \\
\quad \text { using the analytical hierarchy process (AHP) }\end{array}$ \\
\hline Williams $2015^{79}$ & Australia & $\begin{array}{l}\text { Scoping review on organizational barriers to use of evidence (49 } \\
\text { articles included in this study, there were } 29 \text { cross-sectional surveys, } 6 \\
\text { descriptions of specific interventions, } 7 \text { literature reviews, } 4 \text { narrative } \\
\text { reviews, } 9 \text { qualitative studies, } 1 \text { ethnographic study and } 1 \text { systematic } \\
\text { review). Major barriers were } \\
\text { - Workload } \\
\text { - Other staff/management not supportive of EBP } \\
\text { - Lack of resources } \\
\text { - } \quad \text { Lack of authority to change practice } \\
\text { Workplace culture resistant to change }\end{array}$ \\
\hline Wilson $2013^{71}$ & Canada & $\begin{array}{l}\text { Meta-review based on Health Systems Evidence Web site } \\
\text { - Describes the content of systematic reviews on health system } \\
\text { topics available through the Web site, their quality and } \\
\text { recency } \\
\text { - Describes availability of user-friendly summaries }\end{array}$ \\
\hline
\end{tabular}

